\title{
Funde von Steingeräten aus altpleistozänen Schottern im Raume von Wien ${ }^{1}$ )
}

\author{
Von H. Mohr, Wien, und M. Motts, Graz \\ Mit 12 Abbildungen im Text
}

$\mathrm{Z}$ us a mme nf assung. Durch die fast gleichzeitig geglückten Funde von sehr altertümlichen Steinwerkzeugen im Neckargebiet (durch A. RuST) und im Donaugebiet (durch H. MoHR und H. KüPPER) ist die Frage der Existenz einer bodenständigen Industrie zur Zeit des Heidelberger Vormenschen (oder eines Vorgängers) in Mitteleuropa bejaht worden.

Die zur Beschreibung gelangenden Geräte wurden aus dem höchsten und jetzt als basalpleistozän erkannten Schotterkomplex im Raum von Wien (Laaer Berg - Wiener Berg) aufgesammelt. Es ergaben sich klare Beziehungen (sowohl in typologischer als in schlagtechnischer Hinsicht) zum Gerätebestand der Heidelberger Stufe im Neckargebiet. Nach M. Motru ist die Industrie der Laaer Berg-Schotter im Wesentlichen als eine Geröll-Abschlag-Industrie mit starker Betonung der Nasenschaberformen zu bezeichnen. Die - spärlichen - Wirbeltierfunde aus den Schottern sprechen eindeutig für die basale Stellung des Schotterkomplexes innerhalb des pleistozänen Systems. Anknüpfungspunkte, die eine Verbindung zur Faustkeilentwicklung herstellen würden, konnten nicht nachgewiesen werden.

$\mathrm{Summary}$ : Stone implements which nearly at the same time have been found in the Neckar region (by A. Rust) and in the Danube region (by H. MoHR and H. KüPPER) have approved the existence of an industry belonging to the Homo Heidelbergensis (or pre-Heidelbergensis)-period in Middle Europe.

The present paper deals with the implements which have been found in the Danube district. The history of the discovery, the geology of the finding places and the material of the artifacts are treated by H. Moнr (Vienna). On the other hand, M. MоттL (Graz, Styra) tries to throw light upon the typology of the artifacts and upon the relations to other prehistoric cultures. Moreover she discusses some problems belonging to the age of the finding strata. The implements of the Laaer-Berg have been collected within the river gravel complex which has the highest topographical position in the environs of Vienna.

Cestain relations concerning the typology and technique have been found out with the Heidelberg stage, Germany. In the main it is a "pebble flake-tool“ industry with great accentuation of the "nose scraper"-type.

Beyond that there are some blade-like implements. Rare specimers of vertebrates collected within the gravels give evidence that the gravel complex of the Laaer Berg belongs to the basis of the Pleistocene. Any connections with the "core-biface"-tradition (Abbevillian) have not been found.

In h a $1 \mathrm{t}$ :

Fundgeschichte. Von H. MoHr.

Fundstellen und -horizonte. Von H. Mohr.

Der Werkstoff der Geräte. Von H. MoHr.

Beschreibung der Funde. Von M. MotrL.

Kulturbeziehungen. Von M. MotrL.

Stratigraphische Fragen. Von M. Motтl.

Fundgeschichte. Von H. Morr.

Im Jahre 1947 kam der Verfasser durch seine Lehrtätigkeit an einer Wiener Hochschule mit den Ablagerungen des Laaerberges im Wiener Becken in nähere Berührung. Die zahlreichen, tiefreichenden Aufschlüsse, die Ziegelton-, Sand- und Schottergruben boten vielfach Gelegenheit, mit den Hörern Probleme der grundlegenden und der technischen Geologie zu studieren und zu erörtern.

1) Diese Arbeit wurde zum großen Teil durch ein besonderes Entgegenkommen der Direktion der Geologischen Bundesanstalt in Wien (Dozent Dr. H. KüPPER) ermöglicht, welche dem einen von uns einen Arbeitsplatz in den Amtsräumen der Anstalt zur Verfügung stellte und für die durchzuführenden Untersuchungen die Benützung der notwendigen Arbeitsmittel gestattete. Für diese Förderung möchte der Begünstigte an dieser Stelle seinen besonderen Dank zum Ausdruck bringen. (H. Moнr.) 
Schon bei einer orientierenden Begehung (1947) überraschte den Verfasser nahe der Gradener Kapelle (Laaer Bg. P. 241) die der Fazies nach auffallende Übereinstimmung der obersten Bodenschichten mit jenen des Fredamberges bei Brünn-Brno (CSR), einem dem Verfasser durch eigene Aufnahmetätigkeit gut bekannten Gelände.

Die Terrassenstratigraphie des erwähnten mährischen Gebietes beschäftigte den Verfasser viele Jahre (1933-1945), noch mehr die Tatsache, daß es im Bereiche der dortigen vor-Riß(Saale-)zeitlichen Baustufen (=Terrassen) Flußgeschiebe gab, die durch ihre eigenartige Form dem Geologen sofort auffallen mußten. Da der Verfasser immer mehr zur Uberzeugung gelangte, daß in diesen ungewöhnlichen Formen eher primitive Gerätetypen uralter Kulturen, als durch Naturkräfte geschaffene Produkte zu erblicken seien, sah er sich veranlaßt, über diese Funde der Fachwelt zu berichten (1933, 1936, 1939, 1940, 1942). Die oftmalige Wiederkehr der gleichen Bearbeiturgsart (Arbeitsbuchten), der gleichen Form (schnabelförmig zugespitzte Geschiebeformen z. B.) und des gleichen Rohgutes ( $\mathrm{z}$. B. Jurahornstein des Inventars der $35-45 \mathrm{~m}=\mathrm{D}$-Baustufe, Riß-Terrasse; Süßwasserquarzit des Inventars der Fredamberg-Terrasse östlich von Brno, 90-97 m-Baustufe) wirkte auf den Verfasser besonders überzeugend.

Wie die viel umstrittenen Typen der englischen "Crag-Serie“ wurden auch die altpleistozänen Artefaktfunde Mährens nur von wenigen Fachwissenschaftern als artefizielles Inventar anerkannt (K. Absolon 1933, J. S. Skutıl 1938-39).

Bei der Gradener Kapelle (P. $241 \mathrm{~m}$ üb. d. M.), am Südrande des Laaerberges, sind die obersten Schichten durch eine nach $S$ führende Straße bis zu einer Tiefe von $1.5 \mathrm{~m}$ (bis $2.0 \mathrm{~m}$ ) angeschnitten. Man sieht grobe, fast nur aus Quarzit- und Gangquarzgeröllen bestehende Schotter, welche durch einen kreßroten, sandigen Lehm gebunden sind. Da zudem die relative Höhe über dem Donauspiegel ungefähr jener der FredambergTerrasse über der Zwitte in Mähren entsprach, machte sich der Verfasser, - unbekümmert um das damals in der Fachliteratur Osterreichs vertretene mittelpliozäne Alter der Schotter - daran, auch in den Laaerbergschottern im Raume Wiens nach Artefakten $\mathrm{zu}$ suchen.

Das Ergebnis war überraschend: Bald hatte der Verfasser aus den Schottern im Sockel der Gradener Kapelle mehrere, mehr oder minder ovale, zumeist flache Gerölle herausgezogen, die eine, den mährischen Funden ähnliche auffällige Veränderung ihrer Geröllform erkennen ließen. ${ }^{2}$ )

Der Verfasser selbst setzte die Durchforschung der alten Baustufen im Raume Wiens fort und konnte bald im Verbreitungsgebiete der Laaerberg-, der Wienerberg- (J. FINK 1953) und der Arsenalterrasse neue Fundstellen feststellen.

\section{Fundstellen und - horizonte. Von H. Mohr.}

Als ergiebigster Fundraum hat sich der Sockel der Gradener Kapelle und deren nächste Umgebung erwiesen. Hier wurden gute Geschiebe mit bezeichnenden buchtförmigen Arbeitskanten (Schulterbildung) „in situ“ gesammelt, darunter eines mit evidenter Veränderung durch Feuereinwirkung.

Einige Funde stammen auch aus der westlichen und östlichen Straßenböschung, die sich an den Aufschluß der Gradener Kapelle anschließt. Etwa 550 m südöstl. der Gradener Kapelle bricht die Hochfläche des Laaer Berges gegen $S$ ab (Abbauwand einer aufgelassenen Ziegelei, heute verstürzt). Hier waren sandige Tegel des Pannons söhlig gelagert aufgeschlossen, darüber eine schwache $(10-25 \mathrm{~cm})$ Schotterlage, mit kreßroten Lehmresten vermischt, und darüber scheinbar ungestörter, einheitlicher Löß. Diese Schot-

2) Von diesen beachtenswerten Funden wurde der Wiener Kreis der Urgeschichtsforscher umgehend in Kenntnis gesetzt. 
terlage lieferte ebenfalls artefiziell veränderte Geschiebe. Das Alter des Lösses konnte bisher leider nicht näher bestimmt werden.

Einige gute Stücke stammen aus den ferrettisierten Schottern der alten Lehmgrube "Filmstadt" (ca. $1100 \mathrm{~m}$ südöstlich P. 255). Auch dort bildet - gestörtes - Pannon die Unterlage.

Nicht wenige Stücke von ähnlicher Formgebung konnte der Verfasser in der aufgelassenen Rudolfsziegelei (auch Löwy'sche Ziegelei genannt) im Vogental (Ostabhang des Laaer Berges aufsammeln. Dieser großartige Aufschluß ist neuerdings von K. KüPPER (1952) und etwas später von J. FINK \& H. MAJDAN (1954) eingehend untersucht und beschrieben worden.

Der Verfasser hält diesen Fundbericht nicht für den geeigneten Ort, um die teilweise etwas abweichende Einstufung der verschiedenen Schotterniveaus im Bereiche des Laaerberges, wie sie ihm aus der Natur hervorzugehen scheint, gegenüber den älteren Auffassungen zu begründen. Dies soll an anderer Stelle erfolgen.

Der Verfasser trifft hier folgende Gliederung (vergl. hierzu die Profile von F. KüMEL 1938, H. KüPper 1952 und J. Fink \& H. Majdan 1954):

W estwand
Unter Grasnarbe
Braunerde
Jüngerer Löß in
Aulehm (an der Basis Seekreide)
übergehend
Obere Schotter, örtlich mit
Rotlehmbeimischung
Untere Schotter, überwiegenden gröber,
sehr licht und ohne Rotlehm-
beimischung
Grundschutt

Unterlage Pannon

\author{
Nordwand \\ Unter Grasnarbe \\ Braunerde \\ Jüngere Lösse, an ihrer Basis örtlich Schot- \\ linsen
}

Mächtige Rotlehmbildung mit deutlicher Rekurrenz in der Mitte

Altere Löße und Schwemmlehme, bzw. Fließerden
(Etwas tiefere Schotter-Terrasse? nur in der Südwand sichtbar).
Unterlage Pannon

Den größeren Teil des Tagbaues (im Osten) hält der Verfasser für stark gestört. Es scheint eine noch im Pleistozän lebendige Verwerfung durchzustreichen.

In den „unteren“ Schottern der Westwand dürfte die Ausfüllung des Hauptgerinnes anzunehmen sein. Sie enthalten bereits stark abgerollte, aus Flußgeschieben geschlagene Werkzeugformen, welche demnach entweder älter als ihre Wirtsschotter oder höchstens gleich alt wie diese sein können. Als gleich alt müssen behauene Geschiebe angesehen werden, denen jegliche Abrollung fehlt. Sie sind außergewöhnlich selten, aber durch „in situ “-Funde nachgewiesen.

Im nördlichen Abschnitt der Westwand folgt auf die „unteren“ Schotter eine 0,07 bis $0,10 \mathrm{~m}$ mächtige Schicht eines krümeligen Kalkschlamms, der von einer kompakten Rotlehmlage (ca. 0,5-0,6 m mächtig) bedeckt ist. Darüber liegen neuerdings Schotter, welche mit Rotlehm vermengt sind ("obere" Schotter). Der Verfasser hält sie für umgelagerte Altschotter. Über den oberen Schottern folgt die ungegliederte Lößwand.

Im südlicheren Abschnitt der Westwand tritt die Rotlehmlage zuerst nur rudimentär auf, dann scheint sie überhaupt zu fehlen und von jüngeren, d. h. umgelagerten Schottern, welche die unteren Schotter unmittelbar bedecken, vertreten zu werden.

Wenn die Rotlehmbildung dem Mindel-Riß-Interglazial zuzuordnen ist (was als sehr wahrscheinlich gelten kann), können sich in den jüngeren Umlagerungsschottern neben dem altpleistozänen Gerätegut noch viel jüngere artefizielle Elemente einstellen. - 
Diese zwei Schotterniveaus müssen demnach - wo es geht streng a useinandergehalten werden. -

Ein weiterer Fundraum ist die Einsenkung des Butterteiches auf der Hochfläche etwa $900 \mathrm{~m}$ nördlich der Kulmination des Laaer Berges. Hier sind die Schotter 3-5 $\mathrm{m}$ mächtig, durchgehend ferrettisiert und durch Kryoturbation (Frostwirbelbildung) arg gestört. Die Unterlage ist wieder sandig-mergeliges Pannon. Eine Lößüberlagerung fehlt. Die Schotterhöhe kann zu etwa 230-235 m üb. d. M. angenommen werden.

Etwas tiefer (nämlich 205-210 m. üb. d. M.) liegen die gleichfalls stark ferretisierten Schotter einer kleinen Grube zwischen Laaerwald-Straße und Battiggasse, etwa $500 \mathrm{~m}$ ostnordöstlich des Butterteiches. Die Auflagerung auf den pannonischen Sanden war früher gut aufgeschlossen. Heute ist die Grube verstïrzt. Hier scheint es sich wohl um eine etwas tiefere Terrasse (etwa Günz II oder J. Fink \& H. Majdan's Wienerberg-Terrasse?) zu handeln. Wir erinnern uns, daß in der Südwand der löwy'schen Ziegelei gleichfalls eine Andeutung einer etwas tiefer liegenden Baustufe entblößt ist. Einige gute Stücke stammen aus der Grube in der Battiggasse. Sie lassen aber keinerlei typologischen Fortschritt gegenüber dem Inventar der höheren Baustufe erkennen. Ein solcher deutet sich eher bei einigen seichteren, bzw. Oberflächenfunden an, die auf der Hochfläche des Laaer Berges bei Erdaushebungen aufgesammelt wurden. Auf sie soll hier im Hinblick auf ihre unsichere stratigraphische Stellung vorläufig nicht näher eingegangen werden ( $\mathrm{da}$ die fast überall nachweisbare Kryoturbation den ursprünglichen Lagerungsverband der Geräte wesentlich verändert haben kann).

Die in der relativen Höhe über dem Donauspiegel übereinstimmenden Schotter des Wienerberges sind bisher auf ihren Inhalt an Geröllindustrien nicht durchforscht worden. Sie sind ebenso fundhöffig wie Schotterplatten etwa gleichen Niveaus südlich der Donau und östlich der Leitha. ${ }^{3}$ )

Nördlich der Donau ist erst ein einziges Hoffnungsgebiet durchmustert worden: die Schotterplatte der Ortlichkeit Herrenholz (P. 249) nördlich von Stammersdorf (Wien N.). Dieses Vorkommen scheint wohl etwas tiefer zu liegen als die Platte des Laaer Berges; Geschiebezusammensetzung und Fazies weisen aber so weitgehende Übereinstimmung auf, daß man mit größter Wahrscheinlichkeit eine Altersgleichheit des Herrenholz-Niveaus mit jenem des Laaer Berges südlich der Donau annehmen kann. Von einer eingehenden Begründung soll hier Abstand genommen werden. Es sei nur darauf verwiesen, daß in den Herrenholz-Schottern die gleichen quarzigen Komponenten auftreten und eine ähnliche dominierende Rolle spielen wie in den Schottern des Laaer Berges, daß ferner unter den kieseligen Geschieben die als Werkgut so beliebten blaugewolkten oder gestriemten Quarzite einen sehr namhaften Anteil ausmachen. Ebenso wenig mangelt den Herrenholzschottern die schichtweise Konglomerierung, die uns von den sog. „unteren“ Schottern in der Rudolfs-Ziegelei bereits bekannt ist.

Mit diesen Parallelen Hand in Hand geht das Auftreten der gleichen Gerätetypen, deren scheinbar etwas spärliches Vorkommen wohl mit der weitaus ungünstigeren Erschließung der Herrenholz-Schotter (durch eine einzige Schottergrube) hinreichend begründet ist. Die Herrenholzschotter ruhen - wie R. GRILL nachgewiesen hat - gleichfalls pannonen Feinsanden auf.

$$
\text { Der Werkst off der Geräte. Von H. Mohr. }
$$

$\mathrm{Zu}$ Geräten geformt findet man nur Flußgeschiebe der Laaerberg-Terrassen und -zahlenmäßig verschwindend - deren Bruchstücke.

$\mathrm{Da}$ dieses Schotterniveau (ebenso wie die tiefer gelegene altpleistozäne Arsenal-Terrasse) eine ganz auffällige Anreicherung der kieseligen Komponente erkennen läßt, ist es

$\left.{ }^{3}\right)$ Ober die besonders typischen Funde H. KüPPERs von der Rauchenwarther Schotterplatte wird M. Motru später Näheres berichten. 
ganz natürlich, daß das Werkgut der Geräte aus einer nicht spröden, sondern zähharten Kieselsubstanz gebildet wird.

Die Kieselsubstanz ist in den Laaerberg-Schottern (und deren Aquivalenten) vertreten durch

verschiedene Quarzite, vor allem durch

Trümmerquarzite, dann durch

Gang- und Schwielenquarz (Hydroquarzite), wie sie namentlich aus dem kristallinen Grundgebirge der Böhmischen Masse und der Ostalpen bekannt sind; seltener durch

Hornsteine (konkretionäre Bildungen in Kalk- oder Dolomitablagerungen), $\mathrm{zu}$ welchen noch

Jaspisgeschiebe von braunroter oder gelbbrauner Farbe kommen. Die Herkunft dieser auffällig gefärbten, dichten und besonders scharf schneidende Scherben liefernden Geschiebe ist oft unsicher, kann sedimär (Radiolatrite), kann aber auch ein entferntes Derivat irgendwelcher Schmelzflüsse sein (aus Serpentin?, aus Porphyrtuffen?).

Und nun das bemerkenswert Auffällige: man findet k e in e Ger ä te a u s di e se m für bestimmte $\mathrm{Z}$ wecke uns sehr geeignet erscheinenden $\mathrm{R}$ ohg ut !

Alle als behauen zu deutenden Geschiebe der Laaerberg-Industrie sind aus Trümmerquarziten geformt, und zwar zum überwiegenden Teil aus einem metamorphen Quarzit, der bei weißlicher Grundfarbe durch bläuliche Wolken und Flecken geflammt oder gestriemt ist. Bei dem massenhaften Auftreten dieser Quarzitart müßte man eigentlich erwarten, daß dieses Gestein im Einzugsgebiet der frühpleistozänen Donau irgendwo, im Böhmischen Massiv oder in der metamorphen Zentralzone der Ostalpen, auf breiter Fläche bloßliegt. Dies wird auch zutreffen, obwohl die Umfragen bei ortskundigen Petrographen bisher zu keinem positiven Ergebnis geführt haben. -

Weitaus leichter ist es - so scheint es wenigstens - die Heimat gewisser feinkörniger quarzitischer Sandsteine ausfindig zu machen.

Das Gerät Abb. 6 und Abb. 7 ist aus dem gleichen Werkgut. Seiner petrographischen Beschaffenheit nach könnte es sehr gut den lichten Werfener Quarziten (Untere Trias) oder den Radstädter Quarziten (Permo-Trias) entstammen (Einzugsgebiet der Salzach-Enns). Aber auch die kieseligen Quadersandsteine der oberen (böhmisch-mährischen) Kreide (Einzugsgebiet der March) sind nicht ganz ausgeschlossen (zumal die typischen schwarz- bis braunrindigen Hornsteine der böhmischen Kreide unter den Geschieben gut vertreten und leicht kenntlich sind.

Sehr bezeichnend ist, daß das Gerät der Abb. 7 und ein zweites nicht abgebildetes (vom gleichen Fundort) eine sehr auffällige Veränderung ihres Aussehens und ihrer Festigkeit erkennen lassen, welche kaum anders denn durch Hitzeeinwirkung erklärt werden kann. Beide sind rötlichbraun bis ziegelrot verfärbt, wobei die Farbänderung auch das Innere des Geschiebes erfaßt hat. Damit harmoniert eine unverkennbare Herabsetzung der Festigkeitseigenschaften (Morschwerden), wie man es z. B. bei feuerfesten Quarzsteinen (Silika- oder Dinassteinen) nach längerem Brand allgemein beobachten kann. Eine aus dem Gerät der Abb. 7 herausgeschnittene Lamelle ließ unter dem Mikroskop neben einem feinmaschigen Rissenetz (Hitzewirkung?), das die Quarzkörner durchzog, auch deutliche Ansätze zur Neubildung von Tridymitsubstanz nachweisen. Da die übrigen Geschiebe und natürlich auch die Geräte aus dem Sockel der Gradner Kapelle durch den Rotlehm des Ferretto nur ganz oberflächlich gefärbt sind (Farbe läßt sich abwaschen) und im Inneren höchstens durch Brauneisen schwach gelbbraun gefärbt sind, ist auch die ziegelrote Färbung als eine Folge der Hitzeeinwirkung $\mathrm{zu}$ betrachten und beweist mit dem morschen Zustande des Werkstoffes und der be- 
ginnenden Umwandlung der Quarzsubstanz in die Tridymitsubstanz, daß dies Gerät einem scharfen Feuer ausgesetzt war.

Der Gerätebestand der Laaerberg-Schotter gestattet demnach einige für die Erkenntnis seiner artefiziellen Bestimmung wesentliche Beobachtungen: Einmal beschränkte sich der Werkstoff der Geräte auf zwei Quarzitarten, einen metamorphen Quarzit mit bläulichen Wolken, dessen Ursprungsgebiet bisher noch nicht bekannt ist, und einen feinkörnigen quarzitischen Sandstein, wahrscheinlich aus der alpinen Permo-Trias, während andere Quarzvarietäten, wie Gang- und Schwielenquarz, dann verschiedene Knollen- und Plattenhornsteine paläozoischen oder mesozoischen Alters als Werkstoff ersichtlich keine Beachtung fanden. Ferner sprechen wichtige Momente dafür, daß einige Funde aus dem Sockel der Gradner Kapelle mit einem Lagerfeuer in Berührung gekommen sind.

Die beiden Rohstoffarten der Laaerberg-Industrie sind in den Schottern des genannten Niveaus reichlich vertreten. Irgendwelche exotische, dem Geschiebebestand also fremde Werkstoffe konnten nicht nachgewiesen werden. -

\section{B es chreibung der Funde. Von M. Motrl.}

Der unlängst erschienenen Veröffentlichung von A. Rust: Artefakte aus der Zeit des Homo heidelbergensis in Süd- und Norddeutschland, Bonn 1956, ist folgender Nachtrag angefügt worden: „Anläßlich der Tagung der Deuqua-Vereinigung in Laufen Anfang September 1955 legten österreichische Kollegen in Wien artefaktverdächtige Quarzitgerölle aus den höchstgelegenen altpleistozänen Donauterrassen von Wien zur Begutachtung vor. Unter den z. T. stark gerundeten Geröllen liegen unverkennbare Geräte der Heidelberger Stufe vor, wie Nasenschaber, Doppelbuchtschaber und Hobelschaber (Stichel). Dieses bisher am weitesten in den Kontinent hineinreichende Fundvorkommen läßt uns glauben, daß wir neben den verschütteten Urströmen des Nordens, sowie des Rheins auch das gesamte Stromgebiet der Donau in den Lebensbereich des Homo heidelbergensis einbeziehen können ... “ Diesem Nachtrag A. Rust's sei es der Verfasserin erlaubt folgende Mitteilungen anzuschließen: Es war bereits im Jahre 1950, als H. KüpPER, Direktor der Geologischen Bundesanstalt in Wien, der Verfasserin einige artefaktverdächtige Funde aus altpleistozänen Ablagerungen des Wiener Raumes zwecks Begutachtung nach Graz brachte. Besonders das eine Stück, von der Fundstelle Rauchenwarth, fand die Verfasserin derart bezeichnend, wenn auch fremdartig in der Reihe unserer gewohnten eiszeitlichen Werkzeugformen, daß sie sich $\mathrm{H}$. KüPPER gegenüber durchaus in positivem Sinn geäußert hat.

In Wien selbst entstand um diese Funde eine lebhafte Diskussion, die meines Wissens großenteils zur Ablehnung der Artefaktnatur dieser Stïcke seitens der Prähistoriker führte. Dasselbe Urteil betraf auch diejenige Fundgruppe, die Professor H. MoHr seit dem Jahre 1947 aus den Laaerbergschottern im SO-Raume von Wien versammelt hat. Im Jahre 1951 wurde mir diese zweite Fundgruppe seitens H. Moнr nach Graz ebenfalls zugesandt. Nun konnte ich feststellen, daß diese Fundgruppe auch Stücke umfaßt, wie sie mir Direktor KüPPER vorgelegt hat. Danach teilte ich $\mathrm{H}$. MoHr meine Beobachtungen mit dem Vermerk mit, daß ich in dem von ihm aufgesammelten umfangreichen Material einige $\mathrm{Stücke}{ }^{4}$ ) als Bestandteile einer uralten, primitiven Geröllindustrie betrachte.

Da die gesamte Terrassenstratigraphie des Wiener Beckens durch die intensive Aufnahmetätigkeit H. KüPPER's und seiner Mitarbeiter ab 1950 sich im Stadium einer grundlegenden Umstufung befunden hat, so schien es angebracht, vorerst eine abwartende Stellung einzunehmen. Die seitdem durchgeführten Untersuchungen und Neuauf-

$\left.{ }^{4}\right)$ Der Großteil des Materials kann nicht als artefiziell betrachtet werden! 
nahmen der Akkumulationsterrassen des Wiener Raumes durch H. KüPPER, B. PLöChinger, R. Grill, F. Brandtner, ferner J. Fink \& H. Majdan erzielten nun eine weitere Festigung der Neueinstufung der einzelnen Baustufen, weshalb an eine nüchtern gehaltene Veröffentlichung der oben erwähnten Artefaktfunde, als weiteren stratigraphischen Beleg aus den altpleistozänen Schottern im Raume Wiens, ernstlich gedacht werden konnte.

Bisher erschien lediglich eine Kurzmeldung seitens H. KüPPER (1952), wonach „auch im Raum von Wien möglicherweise Anzeichen für die Anwesenheit eines primitiven menschlichen Wesens vorhanden sind." Dies war nun die Situation, als H. Morr anläßlich der Deuqua-Tagung im September 1955 in Wien den an der Tagung teilnehmenden Prähistorikern A. Rust (Ahrensburg), H. Schwabedissen (Schleswig) und R. Grahmann (Koblenz) einige Funde aus den Laaerbergschottern zur Begutachtung vorlegte.

Direktor KüPPER schloß einen seiner Vorträge in der Geographischen Gesellschaft in Wien 1951 über seine neuen Pleistozänbeobachtungen im Wiener Becken mit Hinweis auf die von ihm gemachten Artefaktfunde mit folgenden Worten: „Der Geologe kann die Stücke als Schotter ablehnen, der Prähistoriker kann sie als Artefakte ablehnen, doch bleibt zwischen den beiden Meinungen ein Streifen unbekanntes Land, der beackert werden müßte."

Im Sinne dieser so treffenden, nüchternen Außerungen soll nun versucht werden, eine Brücke zwischen den beiden extremen Auffassungen der Fachwissenschaftlern Ớsterreichs zu schlagen um so mehr, da nun ähnliche Funde auch im benachbarten Deutschland entdeckt worden sind. Nach Parallelen muß also nicht mehr in fernen Ländern gesucht werden, da sich auch für unsere geographischen Gebiete eine neue, ferne Welt auftut, womit es empfehlenswert erscheint, unsere heutige Meinung nach 5 Jahren Wartens in Form eines Kurzberichtes niederzulegen. Im folgenden sollen lediglich nur einige markante Formen der beiden Fundgruppen behandelt werden.

I. Die Funde H. K ÜPPER's Wien :

1. Der Fund, der die Bezeichnung Nr. 20 trägt, stammt aus einer Schottergrube östlich des Ortes Rauchenwarth im SO von Wien, wo nach H. KüPPER $(1950,1951)$ auf den Höhen über pannonen Tonen mit eingeschalteten Süßwasserkalklinsen, scharf gegen die pliozäne Unterlage begrenzt, die Ränder einer Quarzschotterbedeckung liegen, die dem Laaerbergniveau entsprechen. Das Stück wurde nicht in situ, aber in der Schottergrube gefunden, und nach $\mathrm{H}$. KüPPER spricht nichts dagegen, daß es ein Bestandteil des Schotters war. Eine natürliche Entstehung des Fundes hielt $\mathrm{H}$. KüPPER ab ovo für nicht möglich.

Das aus einem flachen Geschiebe, aus hartem, feinkörnigem quarzitischem Material angefertigte Artefakt ist meines Erachtens das schönste und beste Stück unter den mir aus den altpleistozänen Schottern des Wiener Raumes bekannten Funden. Das in Abb. 1 dargestellte Gerät ist $9.5 \mathrm{~cm}$ breit, $8.8 \mathrm{~cm}$ lang und nur $2.6 \mathrm{~cm}$ dick. Durch wenige, gröbere, nur auf der Oberscite des Stückes links und rechts angebrachte Abschläge wurde am oberen Ende des Geschiebes eine gut vorspringende nasenförmige Spitze herausgearbeitet, wodurch eine Gerätform entstand, die, gut in die Hand passend, sich zum Stechen, Bohren, Schaben und Abhäuten gleich gut verwenden ließ. Die Retuschierungen beiderseits von der Nase sind deutlich in zwei Reihen angelegt worden, wodurch zwei buchtförmige Ausschnitte entstanden sind. Ein natürliches Entstehen des Stückes ist somir ausgeschlossen.

K. P. OAKLEY (1950) hebt treffend hervor, daß es Naturprodukten immer an logischer Absicht fehlt. Ihre Abschlagschrammen erscheinen in ökonomischer Verschwendung und sind auch verschiedenen Alters. Der vorliegende bezeichnende Fundtyp weist keines dieser Merkmale auf. 


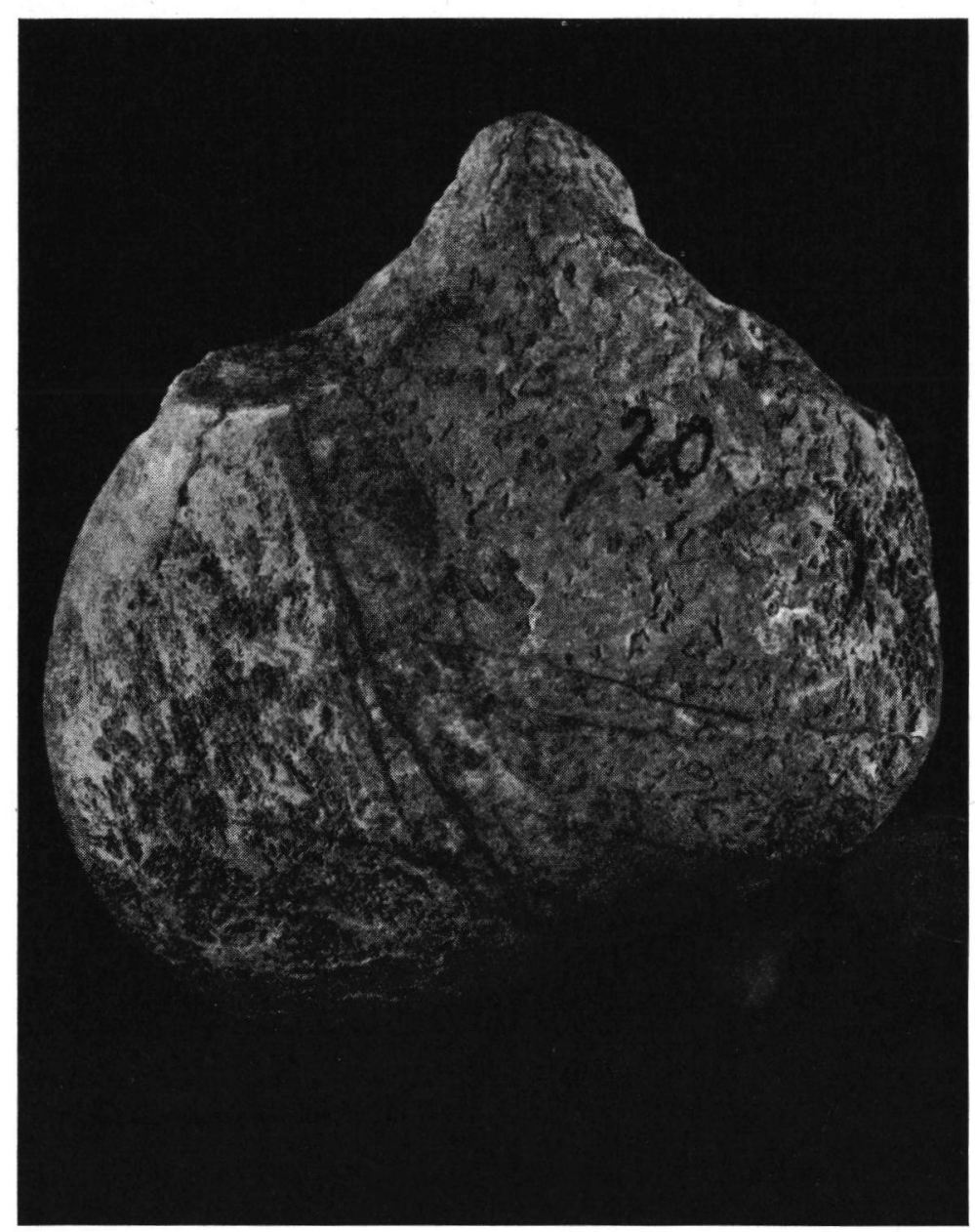

Abb. 1. Spitzer einfacher Nasenschaber. Fundort: Rauchenwarth, im SO von Wien. Nat. Gr.

Die Spitze des Gerätes liegt etwas seitlich zur dessen Längsachse, doch ist die symmetrisch-harmonische Formgebung des Fundes auffallend. Das Artefakt weist sonst keine anderen Bearbeitungsspuren, Beschädigungen oder eine Abrollung auf. Die Buchten beiderseits von der Nase sind nicht übersteilt, so daß das Gerät vermutlich nicht nur mit der Spitze, sondern auch mit den Seitenretuschen als Werkkanten verwendet wurde.

Das äußerst charakteristische Stück entspricht dem Typ der sogenannten einfachen Nasenschaber unter den Leitformen der von A. Rust (1956) aus altpleistozänen Schottern Süd- und Norddeutschlands erst unlängst entdeckten und von ihm als $\mathrm{He}$ idelb e r g e r K u ltu r bezeichneten Geröll-Abschlagindustrie (s. besonders Taf. 4, Abb. 3, Taf. 13 und Taf. 30 seines Werkes). Erwähnenswert ist jedoch, daß die von A. Rust abgebildeten Fundstïcke zumeist massiver-plumper, mit dickerem Griffende sind; die flach-elegante Form des Wiener Fundes erreichen sie nicht.

Die Bezeichnung Nasenschaber drückt den wahren Charakter dieser Gerätformen natürlich nicht aus, da es sich um Universalwerkzeuge handelt, die mehrfachen Zwecken dienten. Doch finde ich die Rust'sche Bezeichnung derart passend, daß sie für unsere 
entsprechenden Typen, auch schon der einfacheren Arbeitsmethode wegen, ebenfalls angewendet werden soll.

2. Demselben Typ entspricht ein weiterer, von H. KüPPER in Wien, IV. Bez., Kolschitzkygasse, aus einer, in den dortigen Terrassenschotter eingesenkten Grube aufgesammeltes Stück. Der Ausfüllungsschotter der Grube war auffällig locker gelagert. Es war kein in die Terrasse eingeschaltetes Bachgerinne; doch läßt sich über das Alter der sekundären Ausfüllung leider nichts Konkretes aussagen. Das $8.3 \mathrm{~cm}$ breite und $9.8 \mathrm{~cm}$ lange, aus einem flachen Quarzitgeschiebe geschlagene Stück (Abb. 2) ist ebenfalls nur auf der Oberseite bearbeitet worden. Die Spitze des Gerätes ist ausgeprägt, wie beim vorigen Fund, die Retuschierungen der links und rechts von der Nase sich befindlichen Buchten sind jedoch gröber. Entlang eines alten, dem Geschiebegefüge entsprechenden Sprunges ist das Stück beschädigt worden. Die Nase des Artefaktes liegt in der Längsachse des Geschiebes.
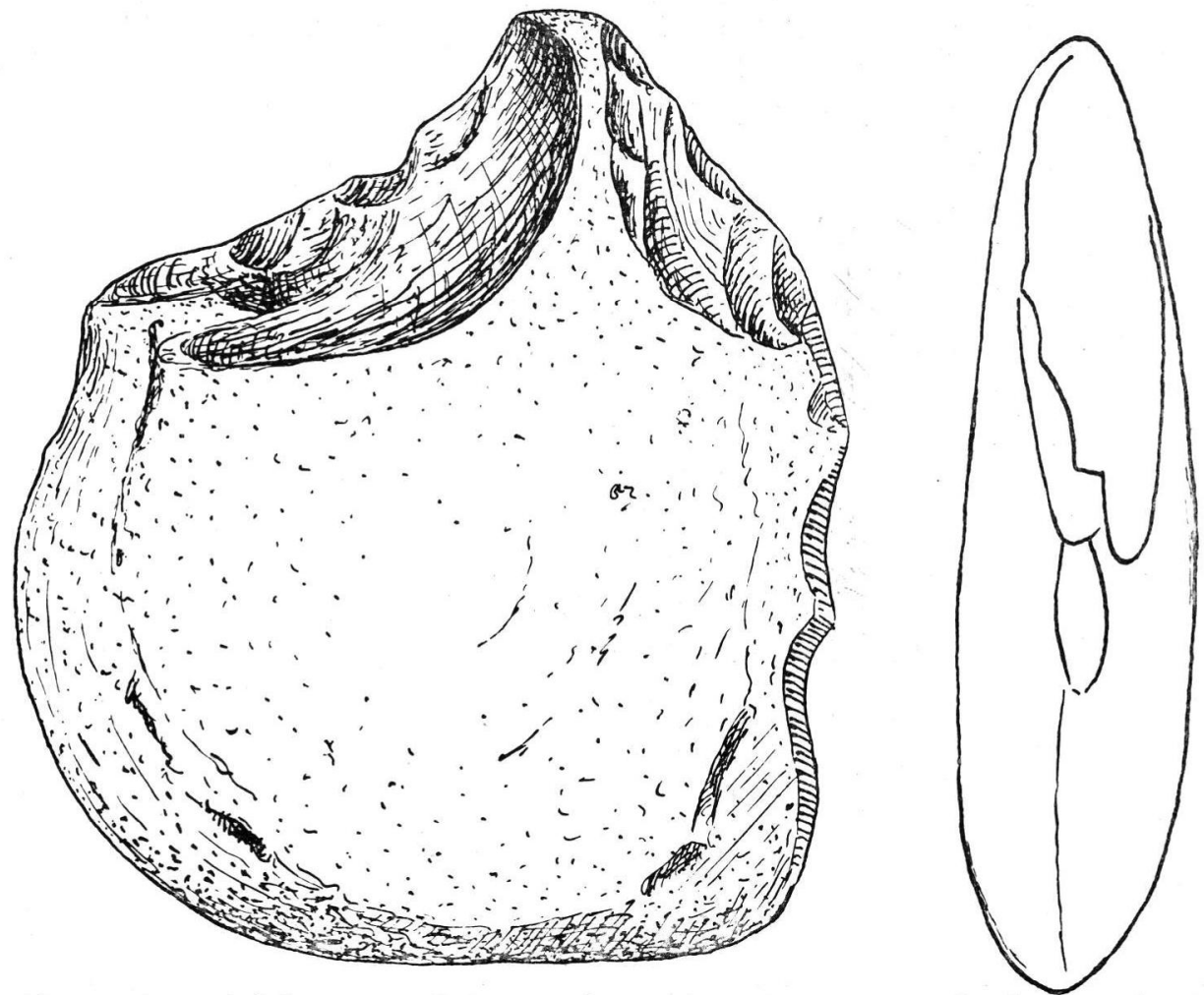

Abb. 2. Spitzer einfacher Nasenschaber. Fundort: Wien IV. Bez. Aus sekundärer Grubenausfüllung. Nat. Gr.

3. Der von H. Küpper mit Nr. 13 bezeichnete Fund wurde leider ebenfalls auf sekundärer Lagerstätte, in einem Schotterhaufen gefunden, der beim Säubern des Untergrundes eines Schrebergartens (Wien X) angelegt worden ist. Aus einem großen $14.5 \mathrm{~cm}$ langen, $10 \mathrm{~cm}$ breiten, oval-flachen Quarzitgeschiebe wurde mittels zahlreicher, feinerer Retuschen eine weit vorspringende scharfe Nase, Bohrerspitze herausgearbeitet (Abb. 3).

Die Retuschen sind an der Nase sorgfältiger als an der ïbrigen Gerätfläche ausgeführt, auch ist bei der Anfertigung des Artefaktes eine weit ausgedehntere Fläche der Oberseite als an sämtlichen anderen Funden behauen worden, ähnlich dem „Gerättyp mit Bucht" auf Taf. 25 der Abhandlung Rust's. 


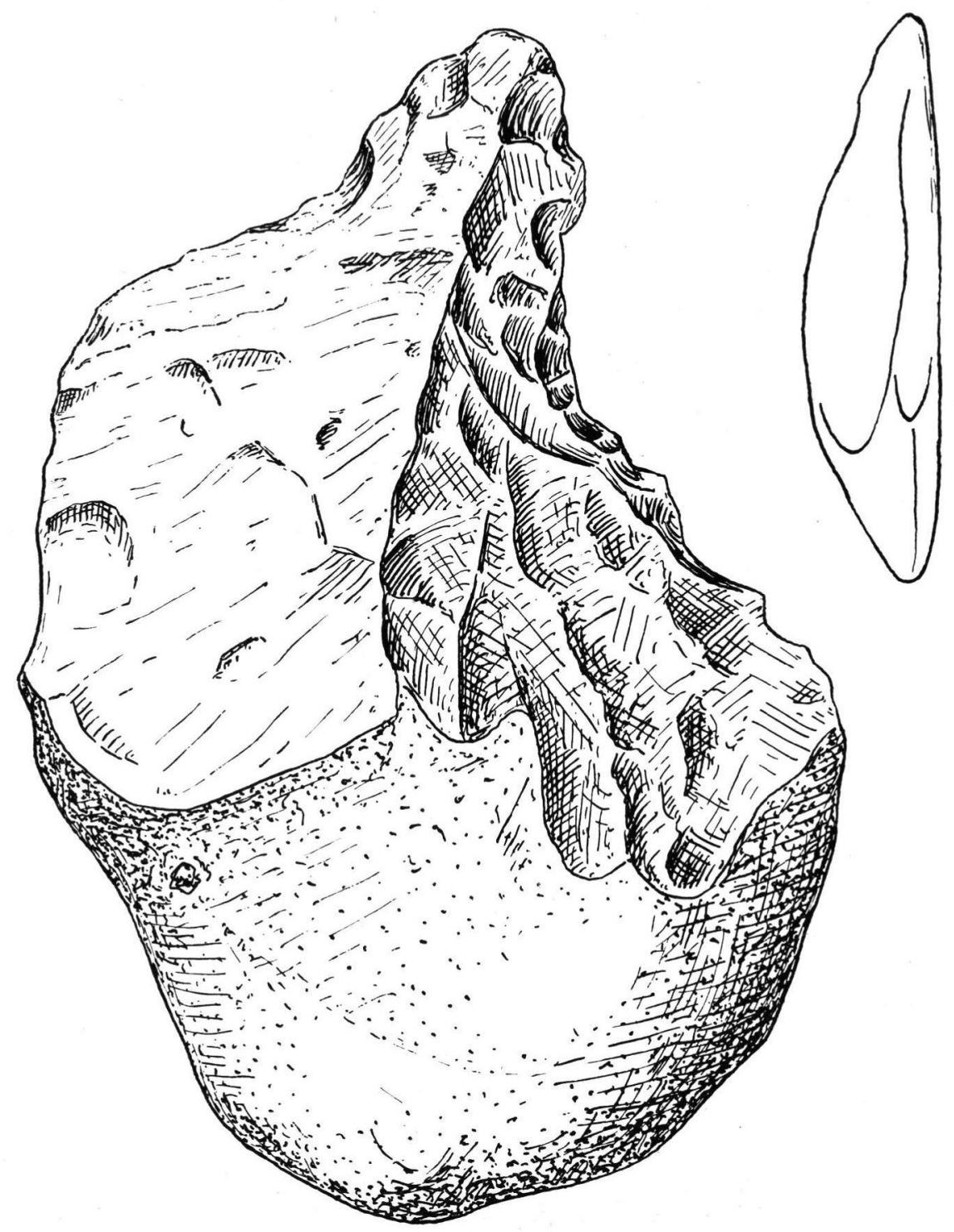

Abb. 3. Fortschrittlicherer Nasenschaber-Typ. Fundort: Wien, X. Bez. Von sekundärer Lagerstätte. Nat. Gr.

Die rechte Flächenhälfte der Oberseite trägt reichlichere Schlagmarken, wodurch von der Spitze bis zur Mitte der Oberseite eine scharfe Kante herabzieht. Links und rechts davon sind die Gesteinsflächen dachförmig abgeschrägt worden. Die Unterseite des. Artefaktes ist glatt, unbearbeitet. Sie trägt noch die ursprüngliche Geröllrinde, wie auch das untere Ende der Oberseite des Werkzeugs. Das Gerät gehört ebenfalls zur Gruppe der Nasenschaber, obwohl es als ein fortschrittlicherer Typ betrachtet werden kann.

II. Die Fundgruppe H. Moнr's, Wien:

Im folgenden möchte ich hauptsächlich einige der Funde anführen, die fast ausnahmslos aus den oberen Schotterlagen bei der Gradener Kapelle am Laaerberg (241 m 
$\mathrm{SH})$ und deren nächster Umgebung geborgen worden sind, also ein großteils geschlossenes Fundgut darstellen. Nach den Angaben von $\mathrm{H}$. Morr sind die obersten Lagen des Laaerbergschotters bei der Gradener Kapelle in einem Straßeneinschnitt bis auf etwa $2 \mathrm{~m}$ Mächtigkeit angeschnitten und zeigen eine sekundäre Ferrettisierung.

Neben scharfkantigen oder nur wenig abgestumpften Stücken gibt es einige stärker gerollte, wie das ja auch in dem von A. Rust aus der Schottergrube Grafenrain bei Mauer aufgesammelten Material der Fall war.

1. Das aus einem etwas dickeren und rundlicheren Geröll angefertigte Gerät (Abb. 4) vertritt den Typ der einfachen Nasenschaber im Material von $H$. MoHr. Es ist $8.8 \mathrm{~cm}$ lang, $8.4 \mathrm{~cm}$ breit und trägt die Aufschrift: Gradener Kapelle, Ostböschung, oberste Schotterlagen. Das orale Ende, die Nase des Artefaktes, wurde auf der Oberseite des Gerölls, in dessen Längsachse, durch mehrere gröbere Abschläge in derselben Technik wie die Funde von H. KüPPER herausgearbeitet. Die Buchten beiderseits der Gerätspitze sind verstumpft. Das linke untere Ende des Stückes trägt weitere Schlagmarken,wodurch das Gerät den Doppelbuchtschabern A. Rust's, einer ebenfalls bezeichnenden Form der Heidelberger Kultur Deutschlands ähnelt, die nach A. Rust als Doppelgeräte aufzufassen sind. Das Artefakt zeigt im allgemeinen eine schlechtere, gröbere Bearbeitung als der prächtige Fund H. KüPPER's; es handelt sich aber auch um ein grobkörnigeres Quarzitmaterial. Die Unterseite des Stückes ist unbearbeitet.

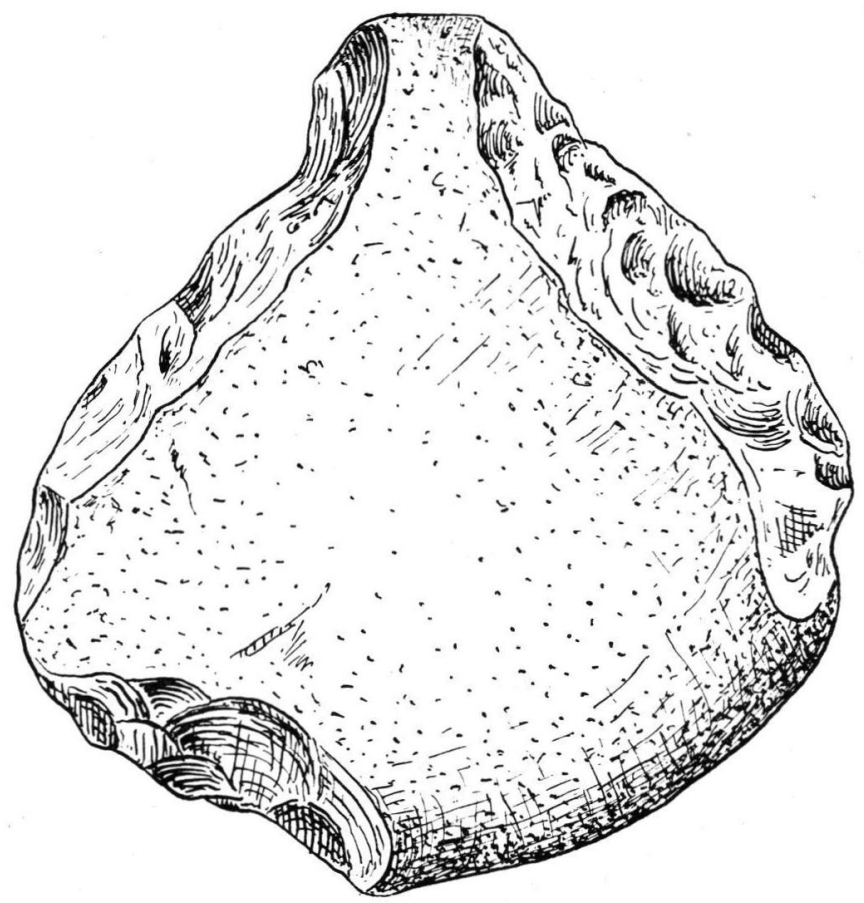

Abb. 4. Einfacher Nasenschaber. Fundort: Gradener Kapelle, Wien Laaerberg. Obere Schotterlagen. Nat. Gr.

Als einfache Nasenschaber können im Fundgut von $\mathrm{H}$. Moнr auch Stücke mit kleineren Ausmaßen (Längen unter $7 \mathrm{~cm}$ ) bezeichnet werden. Sie sind kleinere, aber gute Typen mit zumeist kürzeren-stumpferen Nasenpartien und sind mit dem Fundvermerk: „Basis der Gradener Kapelle, oberste Schotterlagen. In situ“ versehen. 

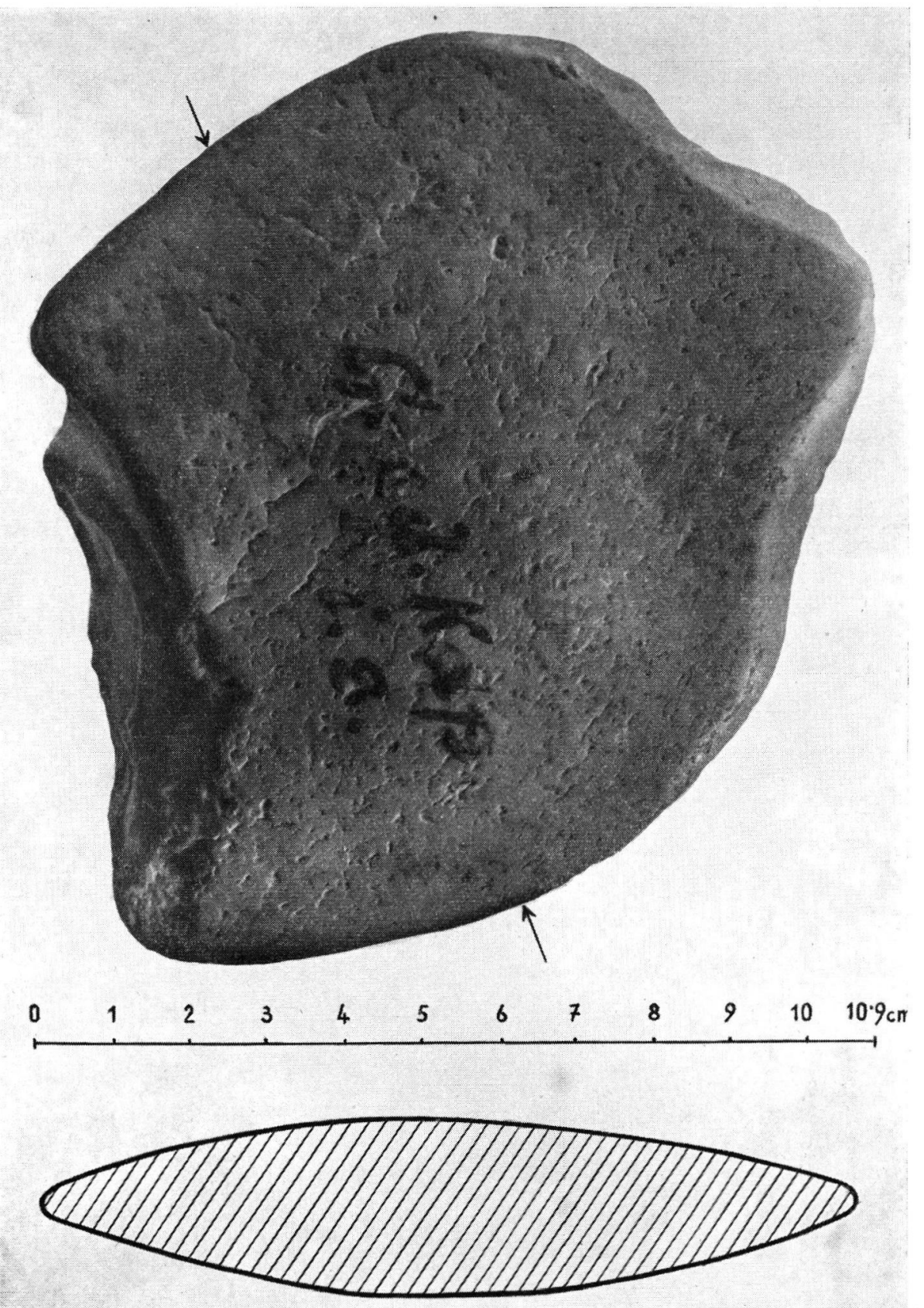

Abb. 5. Gerollter Nasenschaber mit abgeschlagenem unteren Ende. Fundort: Gradener Kapelle, Wien-Laaerberg, obere Schotterlagen. Nat. Gr.

2. Einen gerollten Typ der einfachen Nasenschaber stellt Abb. 5 dar, der ebenfalls aus der Schotterunterlage der Gradener Kapelle, aus den obersten Lagen der mit kreßrotem Lehm durchsetzten Schottern, d. h. aus der Ferretto-Zone stammt. Beide seichten, 
buchtförmigen Ausschnitte wurden an der Oberseite des Artefaktes angebracht, und die Basis des flach-länglichen Stückes ist wahrscheinlich wegen der besseren Haltung in der Hand, abgeschlagen worden, ähnlich wie dem Nasenschaber auf Taf. 30 bei Rust. Das aus einem dichten, lichten, etwas geschieferten Quarzit zugerichtete Artefakt ist $10.5 \mathrm{~cm}$ lang und $10.9 \mathrm{~cm}$ breit bei einer Stärke von nur $2.3 \mathrm{~cm}$.

Mit der Frage der abgerollten Stücke befaßte sich A. Rust nicht eingehender.

Das Nebeneinandervorkommen scharfkantiger und gerollter Artefakte an einer Fundstelle muß, wenn die beiden Gruppen typologisch und schlagtechnisch voneinander nicht sehr verschieden sind, zeitlich gesehen, keinen größeren Altersunterschied zwischen den beiden Sorten ausdrücken. Es besagt nur, daß sie nicht die Werkzeuge desselben Lagerplatzes sein können. Die gerollten Stücke sind die Hinterlassenschaft ufernah gelegener Rastplätze, die durch ausgiebige Niederschläge in den Fluß gespült oder bei Hochwasser vom Fluß erreicht, mitgenommen und weiter stromabwärts dann wieder abgesetzt worden sind. Auch scheint die „Abrollung“ mancher Stücke eher Korrosionsvorgängen $\mathrm{zu}$ entsprechen, während scharfkantigere Stïcke auf eine rasche Einbettung in eine feine, schützende Sedimenthülle und auf keinen längeren Transport im Wasser hinweisen.
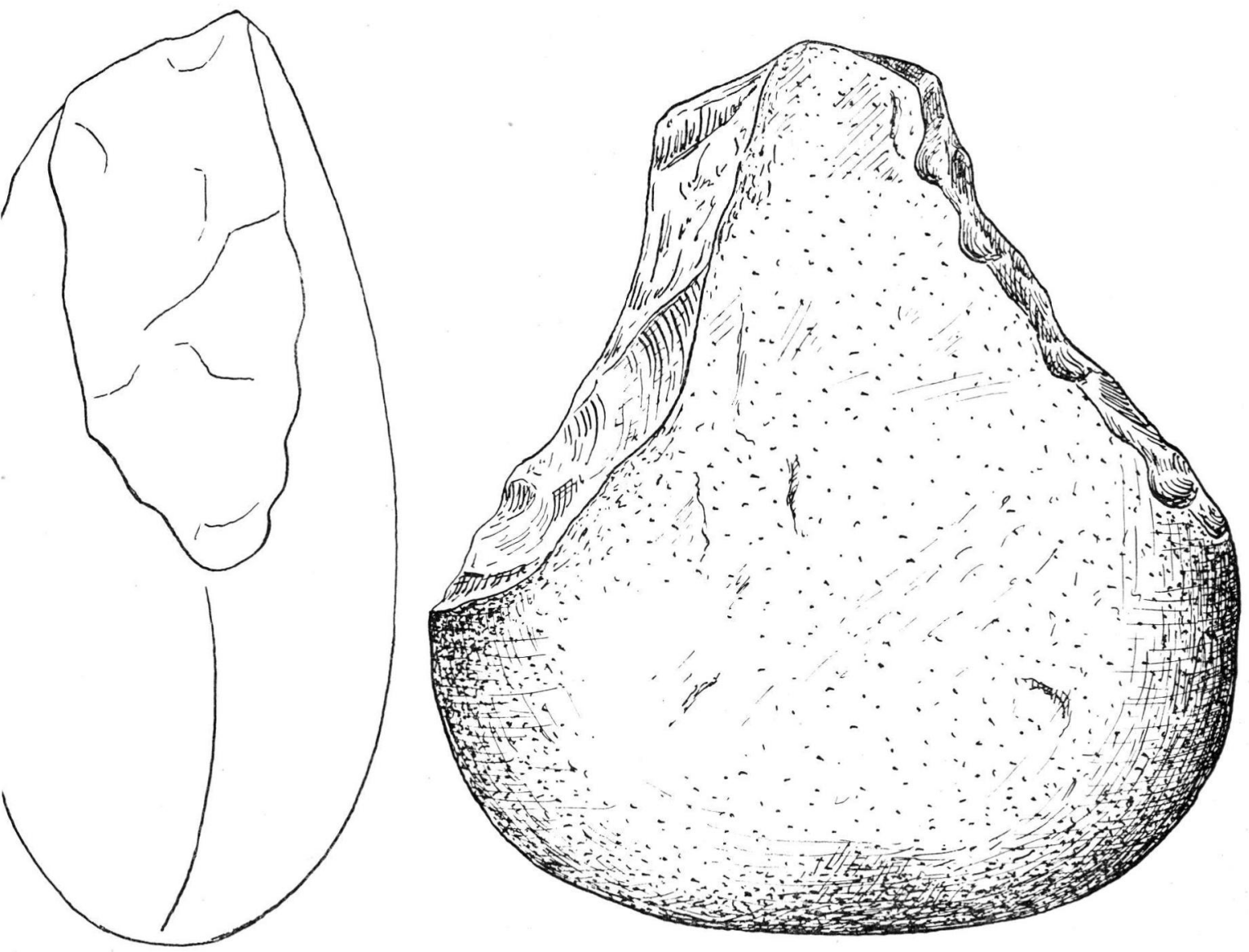

Abb. 6. Nasenschaber mit breiter Spitze und wechselseitig angebrachten Buchten. Fundort: Gradener Kapelle, Wien-Laaerberg, obere Schotterlagen. Nat. Gr. 
3. Einen Nasenschaber-Typ mit wechselseitig angebrachten Ausschnitten möchte ich in Abb. 6 wiedergeben. Er weicht von den oben beschriebenen insofern $a b$, daß sein nasenförmiger oraler Vorsprung verhältnismäßig breit ist und eine deutliche Querschneide trägt und daß die seitlichen Buchten, Hohlretuschierungen, wechselseitig, d. h. der linksseitige übersteilte Ausschnitt auf der Oberseite des Werkzeuges, der rechtsseitige aber auf dessen Unterseite herausgearbeitet worden sind. Die rechtsseitige Bucht zeigt außerdem einen deutlich gekerbten, gezahnten Rand, als wäre dieser durch das mehrmalige Ansetzen eines spitzen Werkzeuges behauen worden. Das aus einem massigeren, dickeren, feinkörnig-quarzitischen Sandsteingeröll geschlagene, $11 \mathrm{~cm}$ lange, $10 \mathrm{~cm}$
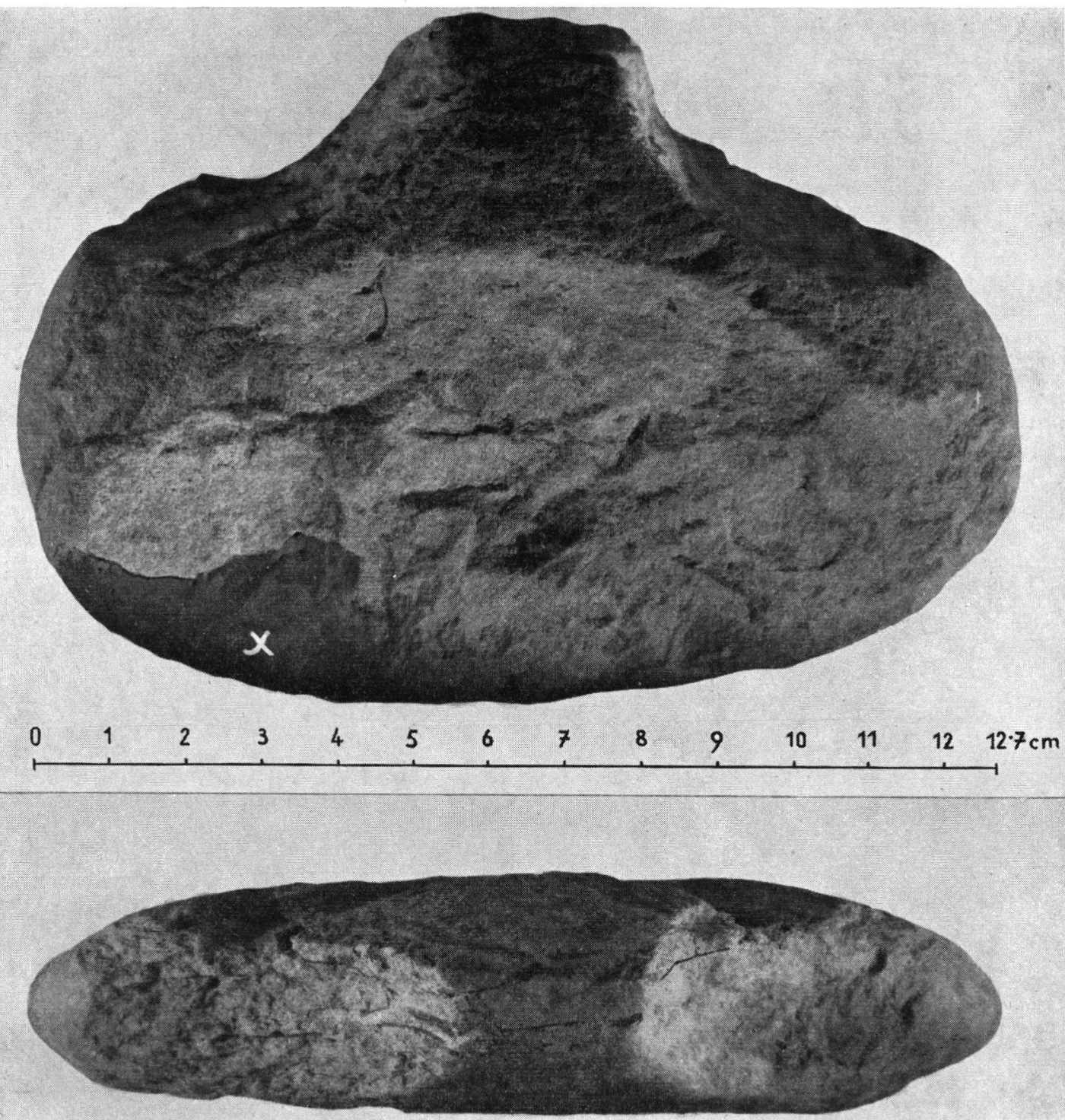

Abb.7. Querovaler Nasenschaber mit breiter Spitze. Fundort: Gradener Kapelle, Wien-Laaerberg, obere Schotterlagen. Nat. Gr. $x=$ mikroskopisch untersuchte Stelle. 
breite und in der Mitte $5.5 \mathrm{~cm}$ dicke Artefakt trägt die Beschreibung: „Gradener Kapelle, Ostböschung, oberste Schotterlagen“. Es zeigt außer den erwähnten Retuschierungen keine weitere Bearbeitung und ist auch nicht gerollt.

Im Fundinventar H. MoHR's konnte ich auch noch einige weitere Stuicke mit wechselseitig angebrachten Buchten nachweisen. An einem Fund ist die Nasenpartie durch ungleich tiefe seitliche Ausschnitte zugerichtet worden, die unregelmäßig versetzte Schlagmarken zeigen.

4. Eine etwas ungewohnte, breit-längliche Form der Nasenschaber-Gruppe bringt die Abb. 7, ein ebenfalls in situ-Fund aus dem ferrettisierten Schotter im Sockel der Gradener Kapelle. Das Material des Gerätes ist, wie das des vorigen Fundes, ein feinkörniger, quarzitischer Sandstein. Die Nasenpartie des $9.5 \mathrm{~cm}$ langen, $13,7 \mathrm{~cm}$ breiten Fundes ist wie bei Abb. 6 breit, die seitlichen Buchten sind sehr tief und mittels wiederholten Beschlagens auf der Oberseite erzeugt worden. Das Artefakt ist nicht gerollt, der untere Teil der Oberseite abgespalten, wodurch eine schiefe-glatte Fläche entstanden ist, die spärliche Bearbeitung zeigt. Nach H. МонR, der ein Stückchen des Artefaktes mikroskopisch untersuchte, zeugen die rötlichbraune bis ziegelrote Verfärbung, der morsche Zustand des Gerölls, sowie die beginnende Umwandlung der Quarzsubstanz in Tridymitsubstanz dafür, daß der vorliegende Fund einer stärkeren Hitzewirkung ausgesetzt war, d. h. vermutlich mit einem Lagerfeuer in Berührung gekommen ist.

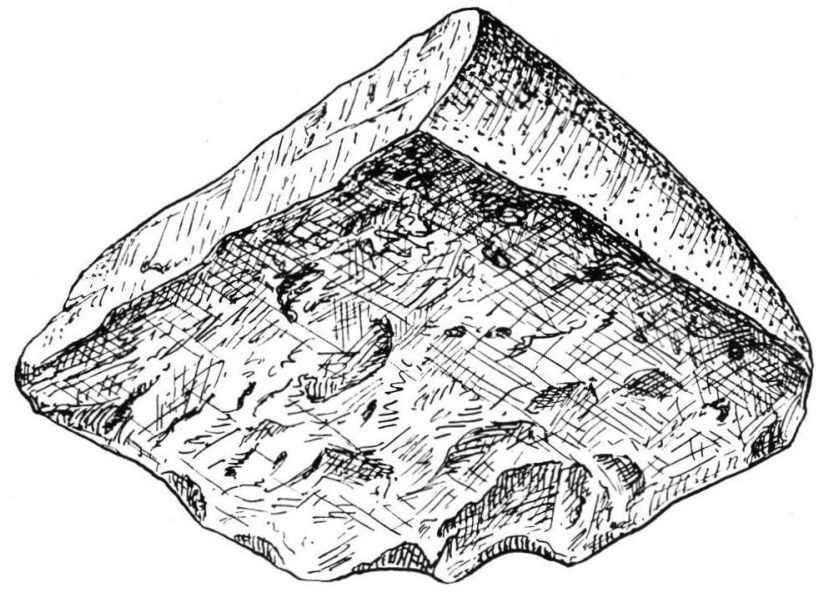

Abb. 8. Schaberabschlag. Fundort: Gradener Kapelle, Wien-Laaerberg. Obere Schotterlagen. Nat. Gr.

5. Erwähnenswert ist eine Schaberform von dreieckigem Umriß im Material aus den oberen Schotterlagen bei der Gradener Kapelle (Abb. 8). Der $5.8 \mathrm{~cm}$ lange und $8 \mathrm{~cm}$ breite Abschlag trägt auf seiner Unterseite die ursprüngliche Geröllrinde, während seine Oberseite abgeflacht und mit schwachen Schlagmarken versehen wurde. Die distale, bogige Schaberkante des Gerätes besitzt mehrere grobe Kerben, der Rand ist gezahnt.

6. Als eine sehr interessante Gerätform erscheint im Fundinventar Gradenerkapelle ein Klingenwerkzeug, wie es Abb. 9 darstellt. Die Unterseite des $7.7 \mathrm{~cm}$ langen und $3.8 \mathrm{~cm}$ breiten Abschlagstückes ist glatt, unbearbeitet. Die linke Hälfte der Oberseite trägt noch die ursprüngliche Geröllrinde, die nur eine große, fazettierte Kerbe am linken Rand unterbricht. Die rechte Hälfte des aus einem schieferigen Quarzit hergestellten Artefaktes ist dachförmig abgeschrägt. Der rechte Rand zeigt gleichfalls mehrere feine Schlagmarken; er ist leicht gezahnt. Am interessantesten ist die Schlagfläche des Stückes, indem sie schräg und glatt ist. Der Schlagwinkel ist ein offener, da er $125^{\circ}$ beträgt, 

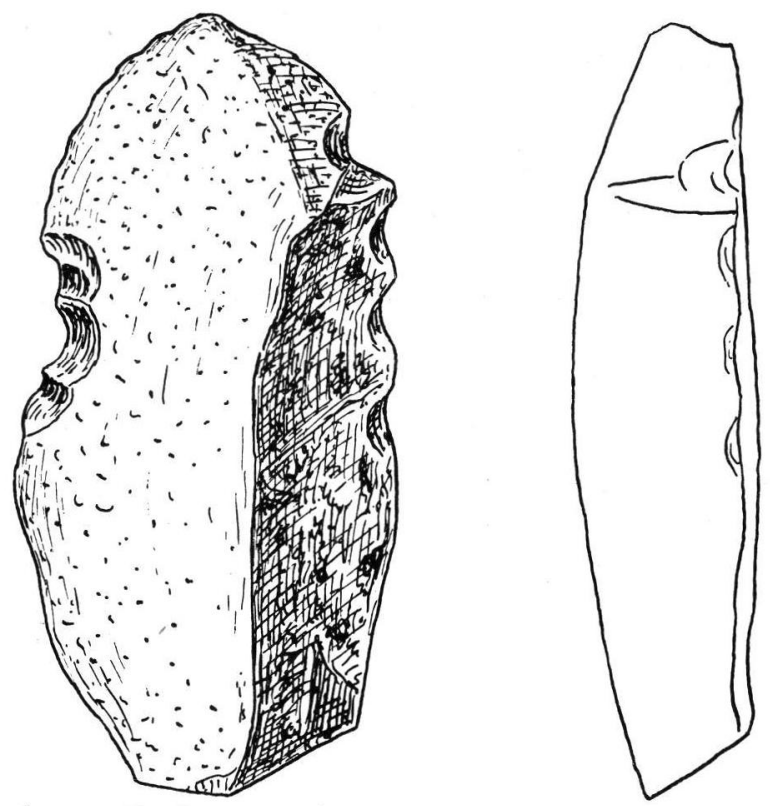

Abb. 9. Klingenwerkzeug. Fundort: Gradener Kapelle, Wien-Laaerberg, obere Schotterlagen. Nat. Gr.

Merkmale, die die Werkzeugformen des älteren Clactonien bezeichnen. Als guterhaltener in situ-Fund wurde er zusammen mit guten, nicht gerollten Nasenschabertypen von H. Монr aus der Ferretto-Zone der Schotter bei der Gradener Kapelle geborgen.

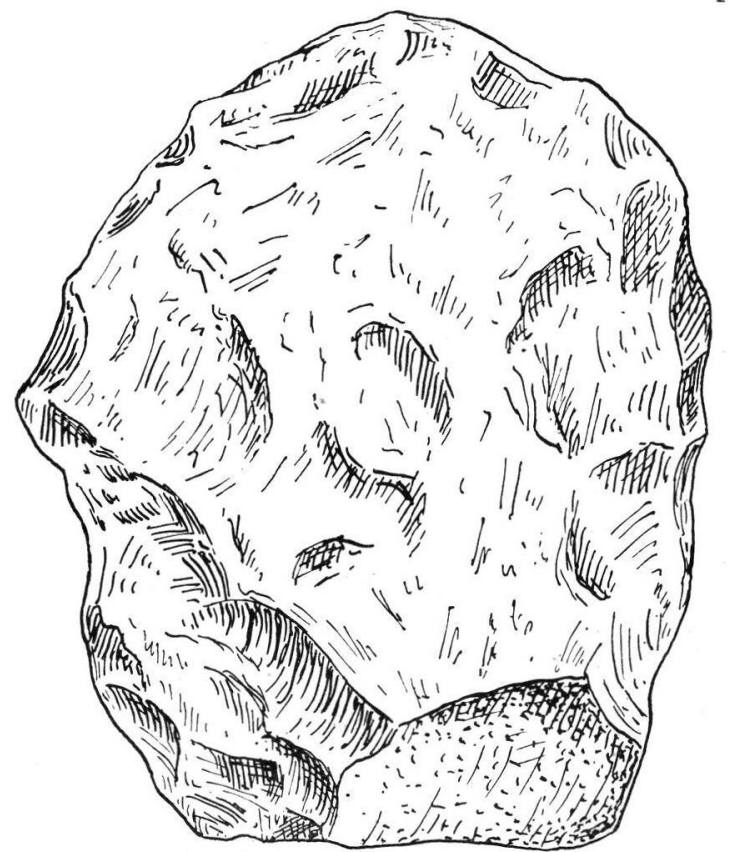

Abb. 10. Klingenabschlag. Fundort: Gradener Kapelle, Wien-Laaerberg, obere Schotterlagen. Nat. Gr. 
7. Ein weiterer klingenförmiger Abschlag soll in Abb. 10 gezeigt werden. Er stammt von derselben Fundstelle. Der Unterseite des Fundes haftet noch die Geröllrinde an, seine Oberseite ist grob behauen. Seine Maße betragen: $8.5 \times 7 \mathrm{~cm}$.

Außer den oben besprochenen Stücken aus den oberen Schotterlagen im Bereiche der Gradener Kapelle möchte ich aus dem Fundgut H. Monp's nur einige Funde anführen, da sie keinem geschlossenem Fundinventar angehören. Doch sind es Stücke, die die Typenreihe aus den altpleistozänen Schottern des Stadtbodens von Wien gewissermaßen ergänzen. So wurde ein gerollter, aber guter Nasenschabertyp mit wechselseitigen Arbeitsbuchten und beschädigter Spitze den ferrettisierten Schottern der alten Ziegelgrube „Filmstadt“ am SO-Hang des Laaerberges entnommen.

8. In den ferrettisierten Schottern der Ostböschung des Butterteiches, einer Einsenkung auf der Hochfläche des Laaerberges (etwa $230-235 \mathrm{~m}$ ü. d. M.) wurde der in Abb. 11 wiedergegebene Fund geborgen. Das aus einem ovalen, flachen Quarzitgeschiebe angefertigte Gerät besitzt eine, zur Längsachse des Fundes quer liegende, durch mehrreihige Dengelung herausgearbeitete tiefe Bucht, die eine an der Abbildung gut zu sehende leicht gezahnte Schaberkante aufweist. Typologisch entspricht dieses Stück den Formen, die A. Rust (1956) als Hohlschaber (z. B. Taf. 2, Fig. 1, und Taf. 4, Fig. 1) bzw. als einfache Hobel (Taf. 17, Sig. 1) beschrieben hat.

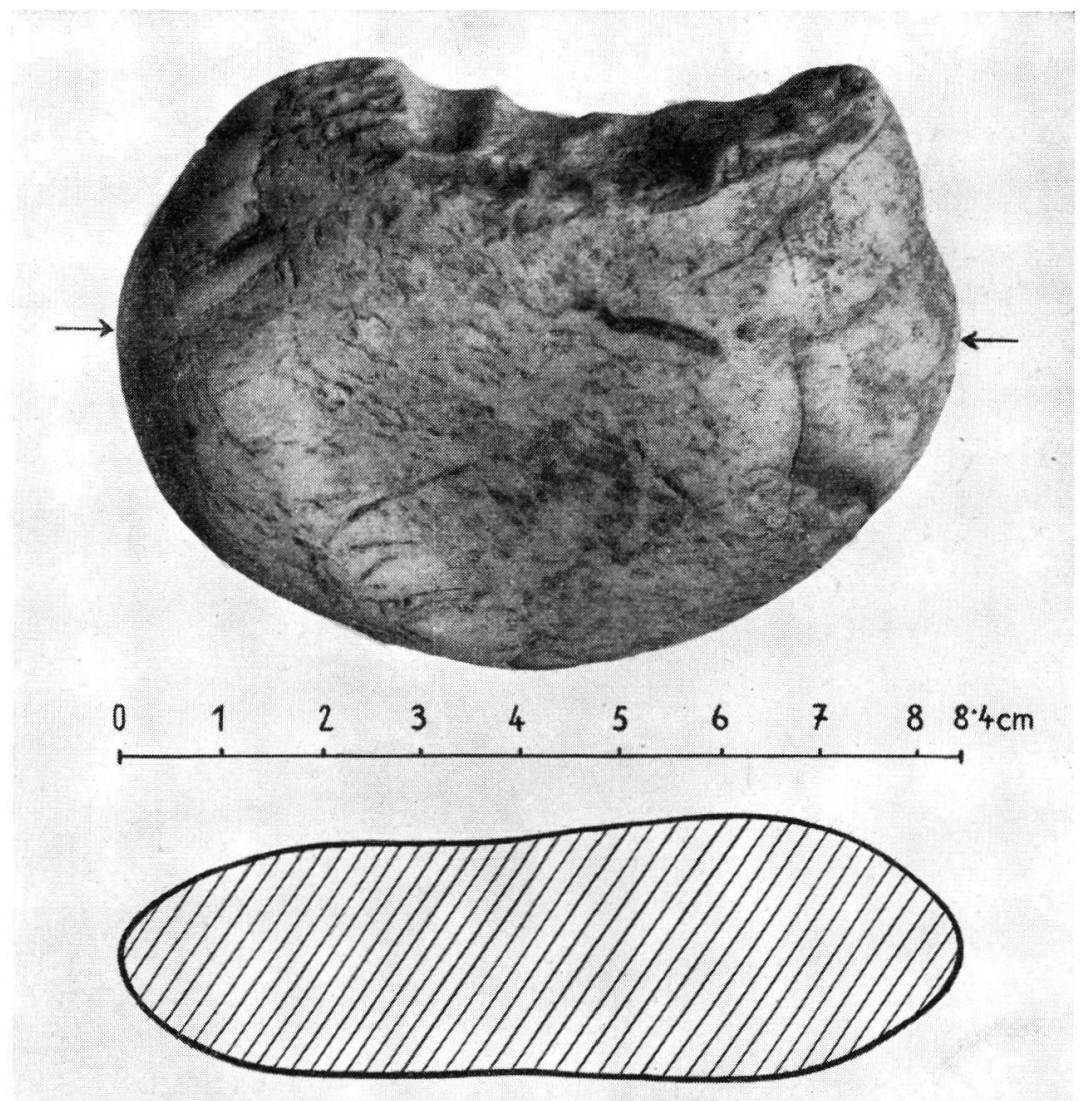

Abb. 11. Hohlschaber. Fundort: Ferrettisierte Schotter der Ostböschung des Butterteiches, Laaerberg. Nat. Gr. 
9. Zuletzt sollen noch drei Funde aus den Rudolf-Ziegelöfen (Löwy'sche Ziegelei) am Osthang des Laaerberges erwähnt werden. Sie stammen nach $\mathrm{H}$. Moнr aus den „unteren" hellen Schottern, die keine Rotlehmbeimischung aufweisen. Alle drei gehören der Gruppe der Nasenschaber mit wechselseitig angefertigten Buchten an.

Das eine Stück, aus der Westwand der Ziegelei, hat eine stark vorspringende, seitlich zur Längsachse des flachovalen Geschiebestückes liegende breite Nasenpartie, die durch ungleich tiefe, seitliche Buchten zugeschärft wurde. Der rechtsseitige, der Unterseite des Artefaktes herausgeschlagene Ausschnitt ist bedeutend tiefer, übersteilt und ohne eine feinere Retuschierung, während die linksseitige seichte Bucht an der Oberseite nur durch wenige Abschläge erzeugt wurde. Das aus einem hellen Quarzit angefertigte Gerät ist $13.7 \mathrm{~cm}$ lang, $9 \mathrm{~cm}$ breit, $3 \mathrm{~cm}$ dick und nur wenig gerollt.

Der zweite Fund aus der SO-Wand der Ziegelei ist stark gerollt, $11.8 \mathrm{~cm}$ lang, $10 \mathrm{~cm}$ breit und $2.5 \mathrm{~cm}$ dick, wurde also ebenfalls aus einem flachovalen Geschiebe geschlagen. Die beiden wechselseitig herausgearbeiteten Buchten sind jedoch gleichmäßiger

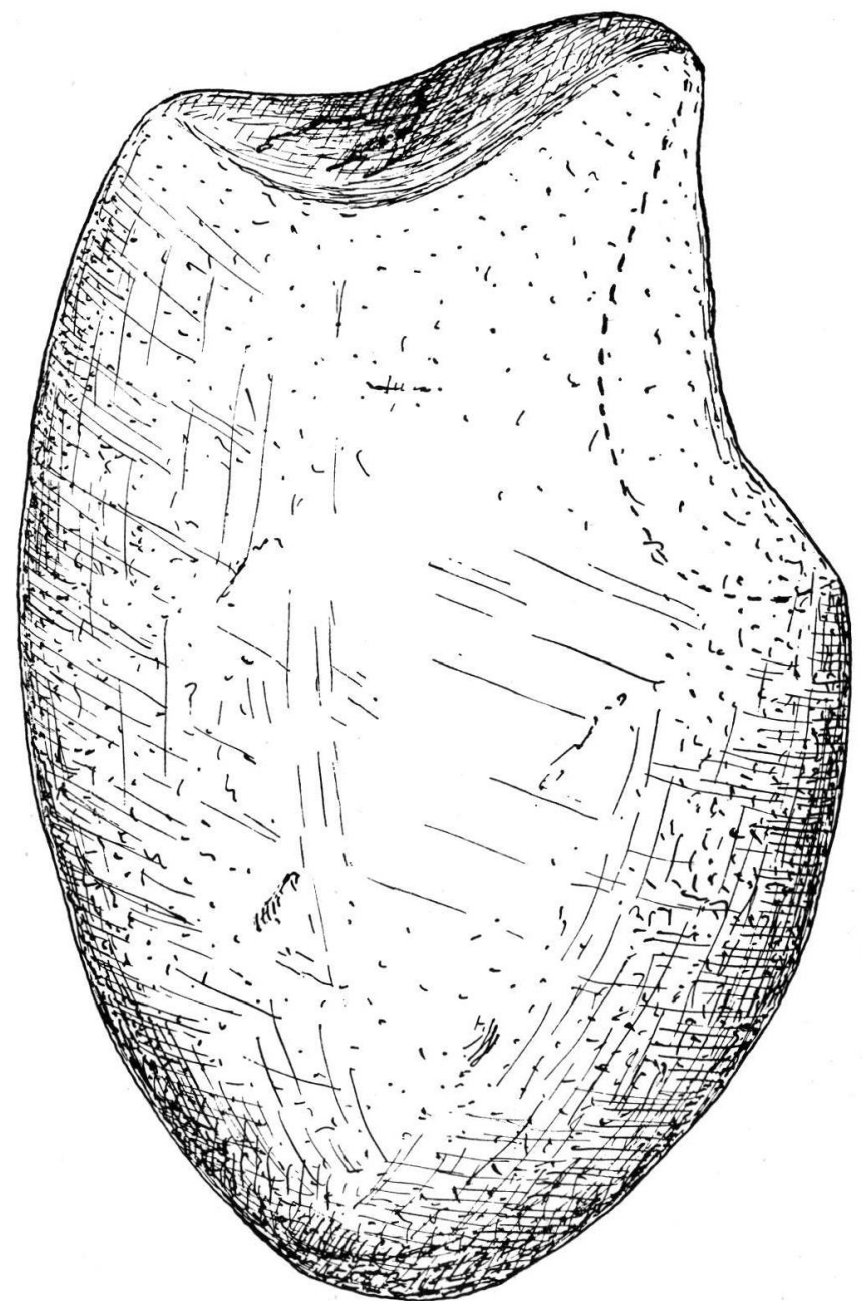

Abb. 12. Spitzer Nasenschaber mit wechselseitigen Buchten. Gerollt. Fundort: Rudolf-Ziegelöfen, Laaerberg. Aus den unteren Schottern. Nat. Gr. 
und die Nasenpartie des Werkzeuges spitzer, schmäler. Es handelt sich also um einen dem Fund von Rauchenwarth recht ähnlichen Typ.

Das dritte Stück von ebendort, das Abb. 12 darstellt, gleicht ganz dem vorigen Fund und ist gleichfalls stark gerollt. Die trotz der Abrollung noch gut vorspringende, zur Längsachse des Geschiebes seitlich liegende Nasenpartie ist schmal, spitz; die wechselseitig herausgearbeiteten Seitenbuchten sind tief und ausgeprägt. Die Maße des Fundes betragen: $13 \times 8.3 \times 3.3 \mathrm{~cm}$.

K ul.turbeziehungen. Von M. Motrl.

Wie eingangs erwähnt, entstand um die Funde H. Küpper's und $H$. MoHr's in den Fachkreisen Wiens eine lebhafte Diskussion. Ich muß selbst zugeben, daß ich, wenn ich nicht zuerst das so gut ausgeführte Stück H. KüPPER's gesehen hätte, die Artefaktnatur der gerollten Nasenschaber-Typen im Materiale H. MoHR's bezweifelt und diese eher für Naturprodukte gehalten hätte.

Doch muß ich den Beobachtungen der Geologen-Kollegen recht geben, wonach man einen Flußschotter, einen sogenannten Restschotter, nicht als ein ungeordnetes Chaos betrachten darf, in dem alle Geschiebeformen und -größen möglich sind. Das lokal gehäufte Vorkommen von extravaganten Formen, wie in unserem Falle im Bereiche der Gradener Kapelle-Laaerberg, ist also an und für sich auffallend; denn wären diese durch natürliche Prozesse entstanden, so müßten sie sozusagen überall zu finden sein, wo z. B. Laaerberg-Schotter erschlossen sind, geschweige denn, daß in Schottern älterer Herkunft, wie z. B. in permischen Schuttbildungen, Gosaukonglomeraten, tertiären Flußablagerungen, nach der Aussage von geologischen Fachgenossen derart geformte Bestandteile nicht $\mathrm{zu}$ beobachten sind.

Ebenso fanden sich in den Laaerbergschottern nicht mannigfaltige Variationen von buchtigen Geschieben, sondern immer wieder Stücke, an welchen die seitlichen buchtartigen Hohlretuschierungen nahe beieinander am oberen Ende der Gerölls anzutreffen waren. Auch trugen diese ovalen Buchtausschnitte immer wieder nur Gerölle aus quarzitischem Gesteinsmaterial, die durch eine große Zähigkeit und Kantenbeständigkeit ausgezeichnet sind.

Als eine heute allgemein bekannte Tatsache wissen wir nun, daß die ältesten Lagerplätze des Menschen in Küstengebieten der Meere oder an den Ufern großer Flüsse entdeckt worden sind. Den Rohstoff seiner einfachen, mit nur wenig Abschlägen zugerichteten Werkzeuge hat er den vorhandenen Schottern entnommen, wobei er durch eigene Erfahrung bald gelernt hat, welche Gesteinsarten in seinem Lebensbereich am besten sich verwenden ließen.

Die von A. Rust abgebildeten, großenteils gut bearbeiteten Nasenschabertypen aus altpleistozänen Schottern Deutschlands erbringen neben obigen Feststellungen die besten Beweise dafür, daß die aus dem Laaerbergschotter stammenden, im vorigen Abschnitt beschriebenen, aus Quarzitgeröllen geschlagenen Stücke, und zwar sowohl die scharfkantigen als auch die gerollten, nicht als durch Naturkräfte erzeugte Formen, sondern als Artefakte zu betrachten sind.

Die Ergebnisse dieser Untersuchungen zusammenfassend, kann vorläufig folgendes mitgeteilt werden:

Aus altpleistozänen Schottern im Raume von Wien liegen Werkzeugformen einer sehr alten Kultur vor, unter welchen verschiedene Typen der von A. Rust beschriebenen Nasenschaber, Hohlschaber oder Hobel, Bogenschaber der Heidelberger Kultur, aber auch Klingenwerkzeuge vorkommen. Die Geräte sind aus handlichen, zumeist flachenovalen Flußgeschieben oder Geröllen, seltener aus Abschlägen durch einseitiges Behauen 
angefertigt worden. Es kann auch eine wechselseitige Bearbeitung des Oberendes der Nasenschaberformen festgestellt werden, die aber immer beschränkt bleibt und in keinem Falle Tendenzen zur Herausbildung einer doppelseitigen Bearbeitungsweise verrät, die zur Formung von rohen, groben Faustkeilen etwa vom Abbevillien-Typ geführt hatte.

Eine beschränkte wechselseitige oder gegenständige Retuschierung einzelner Werkzeuge ist außerdem auch anderen faustkeilfreien Altkulturen eigen, so der Heidelberger Kultur Deutschlands, dem Clactonien Westeuropas und manchen Haugerät-(Chopper-) kulturen Süd- und Ostasiens.

Bemerkenswert ist die bereits erwähnte strenge Auswahl des Rohmaterials der Werkzeuge, indem ausschließlich Quarzite oder selten quarzitische Sandsteine zur Herstellung der Artefakte verwendet worden sind, eine Tatsache, die uns auch im altpleistozänen Fundgut Deutschlands, aber auch in dem von H. BREuIL (1950) beschriebenen ältesten Fundmaterial Frankreichs, ferner in Urkulturen Afrikas und Asiens begegnet.

Der Großteil der vorliegenden Steinwerkzeuge zeigt auch der Größe nach eine gewisse Einheitlichkeit, indem die Längenmaße sich zumeist $\mathrm{z}_{\text {wischen }} 8$ bis $1 \mathrm{C} \mathrm{cm}$ bewegen, während Werte unter 7 oder über $11 \mathrm{~cm}$ seltener sind. Die Mittelwerte der Geräte der Heidelberger Kultur stellen etwas höhere Zahlen dar.

Als eine urtümliche Geröll-Abschlag-Industrie besitzt unser Fundgut, verglichen mit den bisher bekannten aus Geröllen geschlagenen Urkulturen Europas, Afrikas und Asiens, zweifelsohne die größte Übereinstimmung mit der von A. Rust entdeckten Heidelberger Kultur, doch umfaßt jene im allgemeinen besser bearbeitete und auch mehr differenzierte Gerätetypen als unsere „Laaerberg-Industrie“.

In seinen älteren Veröffentlichungen (1954) bezeichnete A. Rust diese Urkultur noch als ein Prä- oder Altabbevillien, ist jedoch in seiner erst unlängst erschienenen zusammenfassenden Publikation ganz der Ansicht, daß die Heidelberger Kultur nicht dem Typenkreis des Abbevillien angehört, sondern daß es sich innerhalb Europas um die Industrien aus zwei eigenständigen Kulturkreisen handelt.

Meine am Artefakt-Material des Wiener Beckens gewonnenen Feststellungen bekräftigen nur Rust's Annahmen. Das Vorkommen eines guten Klingenwerkzeuges, in Clactonart geschlagen, setzt das österreichische Fundgut noch deutlicher vom Faustkeilkreis ab.

Der Gerätebestand von H. BreuIL's „Clactonien ancien“ (1932) ist, wenn auch verhältnismäßig typenarm, so doch schon sehr ausgeprägt und durch die für das spätere typische Clactonien (Clactonien II, Mindel-Riß Interglazial) bezeichnenden Merkmale gekennzeichnet. Gewisse Beziehungen zu diesem Altclactonien stellt in unserem Material lediglich nur das obige Klingenwerkzeug her. Sonst scheinen im Altclactonien Europas keine weiteren Typen des deutschen und österreichischen Fundgutes vertreten zu sein, wie auch A. Rust das Clactonien als eine eigenständige Form des Abschlagkulturkreises ansieht, das mit der Heidelberger Kultur vielleicht im Ursprung verbunden war.

$\mathrm{Zu}$ den ältesten, von vielen Geologen nicht anerkannten Abschlagsindustrien Ostenglands (siehe J. ReID MoIr 1932, Fr. Zeuner 1946 und 1948), so zum Ipswichien, nach ZEuner aus dem Red Crag, Günz I, und zum Norwichien, aus dem Norwich Crag, Günz I-II, sowie zur ältesten Faustkeilkultur aus den Basisschichten des WeybourneCrags (Cromerien, nach ZEUNER Günz II) scheint die deutsche und österreichische Fundgruppe keine Beziehungen gehabt $\mathrm{zu}$ haben. $\mathrm{Zu}$ den einfachen Abschlagerzeugnissen dieser Industrien gesellen sich außerdem rohe Kernstïcke, wie die Rostro-Carinaten, und faustkeilartige Formen vom Typ des frühen Abbeville (siehe diesbezüglich auch WOLDSTEDT 1950). 
Die von H. Breuil \& L. MERoc (1950) aus der $80 \mathrm{~m}$-Terrasse von Mondavezan, Haute Garonne, beschriebenen großen, $13-16 \mathrm{~cm}$ langen, gerollten, aus Quarzitgeröllen nur an einem Ende ein- oder auch wechselseitig nur flüchtig geschlagenen primitiven Artefakte, nach den Autoren prä-Mindel-zeitlich, scheinen ebenfalls jener Reihe anzugehören, die wir durch H. BreuIL \& G. ZByszewski (1942) auch von der Küste Portugals aus der sizilischen Strandablagerung (nach ZEUNER 1946 spätestes Pliozän, nach H. L. Movius 1949 G-M), aber auch aus Nordafrika, Marocco (Arambourg, Mortelmanns, Biberson) kennen und die eine Entwicklung zum frühen Abbevillien erkennen lassen.

Die uns so ferne Gruppe von Urkulturen aus Ostafrika, die durch die Veröffentlichungen von K. P. OAKLEY (1950), L. S. B. Leakey (1951) und H. L. Movius (1953) gut bekannten, durch wenige Abschläge zu einfachen Geräten umgeformten Gerölle aus Lava, Quarz und Quarzit des Kafuan und Oldowan (etwa Günz, Günz-Mindel nach R. Grahmann, 1952 und anderen) tragen ebenfalls die obige, man könnte sagen Zeitsignatur ${ }^{5}$ ). Die Geräte der Oldoway-Beds veranschaulichen besonders gut den Entwick. lungsgang, der von den nur an einem Ende zugeschärften oder zugespitzten urtümlichen Werkzeugtypen, im Gegensatz zu den Beobachtungen am Laaerberg-Material, durch doppelseitiges Beschlagen der Gerölle rings den Kanten entlang zur Entstehung der groben Faustkeile vom Abbeville-Typ geführt hat.

Aus oval-flachen, zumeist Quarzitgeröllen schlug man auch die Geräte der frühen Soan-Kultur NW-Indiens, einer der zahlreichen Haumesser(Chopper)-Kulturen Asiens, über welchen eigenständigen Kulturkomplex von H. L. Movius (1950) zusammenfassend berichtet wurde. Unter den Werkzeugtypen dieser Kultur, die von Movius an die Basis des M-R-Interglazials gestellt wird, gibt es Breitklingenwerkzeuge fast durchwegs mit glatten, nicht fazettierten Schlagflächen und mit hohem Schlagwinkel, sowie viele, nur cinseitig an der Oberseite zugerichtete Gerölle, die noch große Rindenflächen tragen und von welchen z. B. das bei Movius auf Seite 124 in Abb. 18, 6 abgebildete oral zugespitzte Stück große Ähnlichkeit mit unseren Nasenschabern hat. Werkzeuge vom Faustkeiltyp fehlen dieser Kultur.

Beziehungen zwischen dem europäischen Altclactonien und asiatischen Haumesserkulturen sind von verschiedenen Forschern hervorgehoben worden (GrahmanN, OAKLEY, Zeuner, Movius, Breuil usw.), und unter den bisher bekannten Urkulturen Afrikas und Asiens sind es vielleicht Entwicklungsstufen, wie die des nordwestindischen Frühsoans, die auf eine eigenständige Wurzel mancher altpleistozäner Industrien im Bogen vom nördlichen Mitteleuropa bis Westasien hindeuten.

\section{Stratigraphis che Fragen. Von M. Motrl.}

Auf Grund obiger Feststellungen gewinnt natürlich die stratigraphische Einstufung der deutschen und österreichischen Funde sehr an Bedeutung.

A. Rust betrachtet die Neckarschotter von Mauer, die Fundstelle des Homo beidelbergensis, der reichen Säugerfauna und der zahlreichen von ihm geborgenen urtümlichen Werkzeugen, gestützt auf die Auffassung W. SoEngEL's aus dem Jahre 1914 und 1933, als mächtige Flußablagerungen der Günz-Mindel $\mathrm{Z}$ wischenzeit. Doch wies F. Zeuner schon 1945 darauf hin, daß diese jünger sein müssen, und stuft sie, entsprechend der früheren Auffassung von W. Soergel (1928) in das Interstadial Mindel I-II ein.

Auf Grund des eingehenden Studiums der europäischen altpleistozänen Säugerfaunen, so die des Villafranchiens (=Calabrien = Günz)-St. Prestiens $(\mathrm{G}-\mathrm{M})$, bin ich selbst

$\left.{ }^{5}\right)$ Originale des Kafuan sind nach Rust von den Heidelberger Werkzeugen typologisch nicht zu trennen. 
der Überzeugung, daß Mauer dem Mindel I-II und nicht dem Günz-Mindel-Interglazial angehört (1953). Die Waldfauna von Mauer ist eine typische Säugetiergemeinschaft der mindelzeitlichen Elephas antiquus-trogontherii- und nicht der geologisch älteren $E$. meridionalis-Stufe, wie das ja auch die neuen, wertvollen Untersuchungen K. D. AdAM's (1953) bekräftigt haben, wobei dieser innerhalb der Mindel(Elster)-Eiszeit die Mauerer Waldzeit zwischen zwei Steppenzeiten hineinverlegt.

Auf das erdgeschichtliche Alter der von A. Rust (1956) beschriebenen Artefakte aus Norddeutschland soll hier nicht näher eingegangen werden, da diese in jüngeren Grundmoränen sekundär gelagert waren.

H. Breuil $(1932,1950)$ setzt das früheste Clactonien und Abbevillien mit dem G-M an. Die Fauna der Patenstation Abbeville (40 m-Terrasse der Somme), in der bereits primitive Elephas antiquus- und trogontherii-Formen vorkommen, spricht aber schon für Mindel bzw. für ein Mindel-Interstadial. Das typische, bereits sehr differenzierte Clactonien (Clacton II), z. B. von Clacton-on-Sea und Swanscombe, ist auch dem Faunacharakter nach noch jünger: Mindel-Riß-Interglazial.

Im Raume von Wien, südlich der Donau, trennt die Schotterbedeckung der Laaerbergterrasse eine Diskordanz und eine bedeutende Denudationsperiode von den liegenden Ervilienschichten des Sarmats bzw. von den Zonen E (Mittelpannon) und G-H (Oberpannon) des Unterpliozäns (PAPP \& Thenius 1949, H. KüPPER 1950, H. KüPper, A. Papp \& E. Thenius 1952, A. Winkler v. Hermaden 1955); sie stellt somit den Beginn eines völlig neuen Zeitabschnittes dar. Während im südlichsten Wiener Becken, übergreifend auf pannonische Ablagerungen, die dazischen Rohrbacher Konglomerate liegen, fehlt das Daz (=Asti-Stufe) im engeren Raum von Wien, oder es wird mit einer Hipparion crassum führenden Schotter-Sandstrate zwischen Pannon und Laaerbergschotter gerade angedeutet (H. Z

Die durchschnittlich $100 \mathrm{~m}$ über dem heutigen Donauspiegel liegenden Schotter der. Laaerbergterrasse, Aufschüttungen eines Vorläufers der Donau, wurden bis zum Beginn der so aktiven 'Tätigkeit H. Küppen's und seiner Mitarbeiter für mittel- bis basaloberpliozän angesehen. Begründet wurde diese Annahme von G. Schlesinger (1913, 1917) durch die guterhaltenen Funde von Elephas planifrons (Löwy-Ziegelei) und Mastodon tapiroides-borsoni (Schottergrube "Altes Landgut" auf der Höhe des Laaerberges) aus den Schottern der Laaerbergterrasse. E. v. SzÁdEczky-Kardoss wies bereits im Jahre 1938 darauf hin, daß die Laaerbergschotter für jünger gehalten werden müssen und daß sie eigentlich den „Mastodontenschottern“ Ungarns von Pestszentlörinc, Rákoskeresztur, Köbánya b. Budapest zeitlich entsprechen würden.

In den Jahren 1939 und 1942, als ich mich auf Grund neuer, reicher Funde mit der Faunentwicklung des Mittelpliozäns bis Altpleistozäns eingehender zu beschäftigen hatte, fand ich, daß diese Mastodontenschotter und -sande neben altertümlichen Formen wie Mastodon arvernensis, $M$. borsoni, Dicerorbinus megarbinus schon Arten neuer Evolutionsreihen, wie Elephas, Equus, Leptobos führen, Arten, deren Stammesentwicklung sich im Pleistozän fortsetzt, weshalb diese Schotter-Sande als Beginn eines neuen Entwicklungszyklus vom Pliozän abzutrennen und dem basalen Pleistozän anzuschließen wären. Diesem meinen ältestquartären Faunatyp VI = Villafranchien (Calabrien = Auvergneien-Arnien $=$ Günz) reihte ich damals nun auch die Laaerbergschotter zu im Gegensatz zu meinem Faunatyp V = St. Prestien (etwa Günz II und G-M), in dem keine Mastodonten und Hipparionen mehr vorkommen. Dieser Einstufung blieb ich auch in meinen späteren Veröffentlichungen treu $(1950,1953)$.

Eine weitere Stütze für meine Annahme fand ich auch in den Ergebnissen von A. C. Blanc (1942), M. Pfannenstiel (1944) und besonders von H. L. Movius (1949), die das Calabrien-Villafranchien ebenfalls als basales Pleistozän bezeichnet haben. So 
wurden von Movius auch die bishin für Pliozän gehaltenen Mastodonsande Frankreichs ins älteste Pleistozän, in das Villafranchien, gestellt. Das Vorkommen altertümlicher Säugetierarten, wie Mastodon und Hipparion in ältestpleistozänen Ablagerungen ist biologisch eine ebenso natürliche Erscheinung, wie das allgemein bekannte Persistieren mancher Miozänarten (Mastodon angustidens, Anchitherium, Dorcatherium, Lagomeryx) noch im Unterpliozän Europas.

Angeregt durch die Forschungen in West- und Südeuropa, waren H. KüPPER, A. PAPP \& E. Thenrus die ersten in Ósterreich, die sich der neuen Altersdeutung jüngerpliozäner Komplexe angeschlossen haben (1949) und für eine Grenzziehung des Pleistozäns vor dem Villafranchiano = Calabriano, d. h. vor der ältesten Donauterrasse, der Laaerbergterrasse, waren. Wie von den meisten Autoren, so wurde das Villafranchien auch von PAPP \& ThenIUs mit der Günz-Eiszeit parallelisiert. Die klimatischglaziale Natur der Schotterakkumulationen des Wiener Raumes wurde auch von H. KüPPER, FINK \& MAJDAN betont, während A. WinKLeR v. HERMAden (1955) bezüglich der altpleistozänen Terrassen für eine andere Deutung wäre.

H. KüPPER legte sich anfänglich (1950) hinsichtlich einer Verknüpfung der Laaerbergterrasse mit der Günz-Eiszeit nicht fest, und 1952 stellte er die Frage, ob dem Laaerbergschotter mit Rücksicht auf den Hipparion-Fund „nicht etwa der Charakter einer Serie comprehensive zuzuerkennen wäre, welche das jüngste Pliozän und das älteste Pleistozän umfaßt“. 1955 stellt er jedoch in seiner Tabelle XI die Laaerbergschotter im Sinne der konventionellen Quartärgliederung dem Günz-Glazial gleich und hält die lokal auf Laaerbergschotter auftretenden Rotlehme für eine sekundäre Bildung im Günz-Mindel Interglazial.

Bis zur Abtrennung der "Wienerberg-Terrasse“ durch J. FINK \& H. MAJDAN (1954) fungierten als paläontologische Belege für die Laaerbergschotter die beiden von G. SCHLESINGER eingehend behandelten Großsäuger: Mastodon (Zygolophoden) tapiroides-borsoni (M.cfr. borsoni nach E. Thenius 1955) und Elephas (Archidiskodon) planifrons-meridionalis. Beide Formen zusammen ergaben gute Belege für ein ältestpleistzänes Alter der Laaerbergschotter, für ein älteres Villafranchien im Sinne von Movius, PAPP \& THENiUs, Мотть, bzw. für ein älteres Villafranchien normal mit der Koexistenz von Mastodon und Elephas, im Sinne der klassischen Villafranchien-Studien von J. Viret (1954).

Anläßlich der Neuaufnahme der Akkumulationsterrassen des Wiener Raumes wurde von FINK \& MAJDAN (1954) zwischen der Laaerbergterrasse (Günz) und der Arsenalterrasse (Mindel) eine Zwischenterrasse, die bereits erwähnte Wienerbergterrasse, eingeschaltet und danach festgestellt, daß die Schotter im gut bekannten Aufschluß der Rudolf (Löwy)-Ziegelei am Ostabhang des Laaerberges nicht im Bereiche der Laaerbergterrasse, wie das H. KüPPER (1952) angenommen hatte, sondern im Bereiche der Wienerberg-Terrasse liegen. Gleichfalls ist A. W'InkLER v. Hermaden (1955) der Meinung, daß die Schotter der Rudolf-Ziegelöfen nicht dem Laaerberg-Horizont, sondern einem jüngeren eingeschalteten Niveau entsprechen.

Obige Feststellungen müssen uns aus doppeltem Grunde interessieren: erstens stammt der Fund des E. planifrons-meridionalis aus den Schottern der Rudolf-Ziegelei, zweitens wurden nach $\mathrm{H}$. MoHr in den tieferen, nicht rotgefärbten Teilen dieser Schotter ("untere Schotter" nach H. MoHR) abgerollte und selten auch scharfkantigere Nasenschabertypen gefunden, wie das ja anläßlich einer Exkursion der Deuqua-Tagung in Wien auch $\mathrm{H}$. Schwabedissen und A. Rust glückte.

Durch die neue Deutung der basalen Schotterablagerung im mächtigen, stark gestörten Aufschluß der Rudolf-Ziegelöfen als Wienerbergschotter, wurde der Laaerbergschotter stratigraphisch um einen guten Fossilbeleg entkräftet, da zum Beweis des ältestpleistozänen Alters der Laaerbergschotter außer den geologischen und sedimentpetro- 
graphischen Gründen paläontologisch uns nun lediglich der Mastodon cf. borsoni-Fund zur Verfügung steht. Aber auch dieser besagt, daß die Laaerbergschotter als altpleistozäne Akkumulation nicht jünger als Villafranchien sein können, da im St. Prestien (=nach Viret 1954 oberes Villafranchien $=$ Leffe, Senèze, St. Prest, reine MeridionalisTerrassenfauna Ungarns), das von H. L. Movius (1949) und von A. PAPP \& Thenius (1949) ausschließlich mit dem Günz-Mindel-Interglazial parallelisiert wird, keine Mastodonten mehr vorkommen.

Somit dürfte für den schönen Nasenschabertyp H. KüPPER's aus der Schottergrube von Rauchenwarth im Laaerbergniveau, ferner für die zumeist nichtgerollten Artefaktfunde H. Mohr's aus den Schottern um die Gradener Kapelle-Laaerberg als erdgeschichtliches Alter ein älteres Villafranchien, im Sinne einer glazialklimatischen Betrachtung etwa älteres Günz, gesichert zu sein. Der sehr altertümliche Habitus der beschriebenen Stücke würde diese Einstufung durchaus stützen, da im Vergleich zu unseren Funden die Mauerer-Kultur spezialisierter (bessere Bearbeitung der Geräte, an Typen reicheres Inventar) erscheint.

Eine schwierigere Angelegenheit stellt m. E. die stratigraphische Einstufung der Wienerbergschotter der Rudolf-Ziegelöfen dar. Sie wurden von H. Kü:Pper 1955, Tabelle XI, als Kaltstoß I in das ältere Mindel gestellt. Die aus diesen Schottern stammenden wenigen sicheren Artefaktfunde sind zumeist stärker gerollt, und es ist $\mathrm{m}$. E. fraglich, ob sie hier primär gelagert waren.

Ebenso soll erwähnt werden, daß mit dem E. planifrons-meridionalis-Fund, der auch nach E. Thenius (1949) ein altertümlicherer Typ ist, ein mindelzeitliches Alter der Schotter nur schwer gestützt werden kann. Diese altertümlichen Meridionalis-Formen erscheinen nach unseren bisherigen Kenntnissen schon im basalen Villafranchien, d. h. mit der Plio-Pleistozängrenze (Newer Red Crag, Movius, Viret, Papp \& Thenius, MotтL) und sind nach Schaub (1948) und Viret (1954) bis ins obere VillafranchienSt. Prestien zu verfolgen. Gegen Ende dieses Interglazials erscheinen schon die trogontheroiden Endformen der Meridionalis-Reihe, die auch noch im Mindel-Glazial vorkommen (Aalen, Jockgrim = Mindel I, siehe K. D. Adam 1953).

Falls also am Mindel-Alter der Winerbergterrasse aus geologischen Gründen festgehalten wird, so wäre es m. E. empfehlenswert, zu prüfen, ob der Elephas-Fund sich in diesen Schottern auf primärer Lagerstätte befand. Wäre das jedoch der Fall, so sollte vielleicht erwogen werden, ob die Schotter nicht doch älter als Mindel, etwa als jüngeres Villafranchien-St. Prestien, im Sinne einer glazialklimatischen Deutung etwa als jüngeres Günz, zu betrachten wären. Die so spärliche Fossilführung der altpleistozänen Terrassen im Raume von Wien erschwert diesbezüglich die klare Entscheidung.

\section{Angef ührte Schriften}

Absolon K., K. Zapletal, J. Skutil \& A. Stehlik: Bericht d. čechoslovak. Subkommission von "The international Commission for the Study of the fossil Man“. - Mitt. a. d. paläolith. Abteilg. am Mähr. Landesmuseum Nr. 30, Brünn 1933.

K. D. Adam: Die Bedeutung der altpleistozänen Säugetierfaunen Südwestdeutschlands für die Gliederung des Eiszeitalters. - Geol. Bavar. 19, 1953.

P. Biberson: First elements about occurence of "Pebble-culture" in Atlantic Marocco. - Veröffentl. des IV. Inqua-Kongr., Rom 1955.

A. C. Blanc: Variazioni climatiche ed oscillazioni della linea di riva durante l’Era glaziale. Geol. Meere und Binnenwässer 5, Berlin 1942.

H. Breuil: Les industries à eclats du Paléolittique ancien. Le Clactonien. - Le Préhistoire 1, 1932.

H. Breuil \& L. Meroc: Les terrasses de la Haute Garonne et leurs quarzites. - Le Préhistoire 11, 1950. 
H. Breuil \& G. Zbyszewski: Contribution à l'étude des industries paléolithiques du Portugal. Comun. Serv. geol. de Portugal 22, Lisboa 1942.

J. Fink \& H. Majdan: Zur Gliederung der pleistozänen Terrassen des Wiener Raumes. - Jb. geol. Bundesanst. Wien 97, 1954.

R. Grahmann: Urgeschichte der Menschheit, 2. Aufl., Stuttgart 1956.

KüMEL, F.: Der Löß des Laaer Bgs. in Wien. - Führer f. d. Quartärexkursionen des III. InquaKongresses Wien 1936. - - Die Exkursion am Nachmittag d. 5. Sept. 1936 auf den Laaer Berg in Wien. Verh. d. III. Inqua-Kongr. Wien 1938.

KüPPER, H.: Bericht 1949, Quartärbereich. - Verh. geol. Bundesanst. 1949. - - Zur Kenntnis des Alpenabbruches am Westrand des Wiener Beckens. - Jahrb. geol. Bundesanst. Wien 94, 1950. - - Bericht 1950. - Verh. geol. Bundesanst. 1950/51. - - Eiszeitspuren im Gebiet von Wien. - Ber. österr. Akad. Wiss. Abt. I 159, Wien 1950 (1950 b). - - Neue Daten zur jüngsten Geschichte des Wiener Beckens. - Mitt. geogr. Ges. Wien 94, 1952. - Beiträge zur Pleistozänforschung in OOsterreich. - Verh. geol. Bundesanst. Wien, Sonderheft D, 1955.

H. KüPper, F. Brandtner \& B. Plöchinger: Kalk- und Quarzschotter im Pleistozän aus dem Bereich des unteren Fischatales, Niederöst. - Anz. österr. Akad. Wiss. Wien, Math. Nat. Kl. 1951, Nr. 7.

H. KüPPER, A. PAPP \& E. Thenius: Über die stratigraphische Stellung des Rohrbacher Konglomerates. - Sber. österr. Akad. Wiss. Wien, Math. Nat. Kl. I, 161, 7, 1952.

Mонr, H.: Eine Lößbasisindustrie bei Brünn (Mähren, CSR). - Verh. naturforsch. Ver. Brünn 64, S. 146-150, 1933. - - Der vorgeschichtliche Mensch in Mähren älter als die Lößbildung. - Forsch. u. Fortschritte 12, S. 57, 1936. - - Urgeschichte und Geologie. Eine Auseinandersetzung. - Geol. Rundschau 28, S. 465-471, Stuttgart 1936. - - Die Baustufen um Brünn in Mittel-Mähren und ihre Einschlüsse an paläo- und archäolithischen Industrien. - Verh. d. III. Internat. Quartär-Konferenz Wien 1936, S. 1-5, Wien 1938. - - Können die Maloměřitzer Terrassensilices Naturprodukte sein? Verh. naturforsch. Ver. Brünn 70 (1938), S. 1-12, Brünn 1939. - Stellungnahme zu Herb. L ind n e r's Studie über „die saale-eiszeitliche Endstaffel und die Bewegungen des Saales-Eises in Oberschlesien“. - Jber. geol. Verein. Oberschles. 1940, S. 49. - Neuere Ergebnisse der Quartärforschung in Mittelmähren. - Mitt. d. Alpenländ. Ber. 35, S. 215, Wien 1942, S. 215. - - Zur Kenntnis der Quartärforschung in Mittelmähren I. - Abh. deutsch. Akad. Wiss. Prag, 1943.

M. MotrL: Die mittelpliozäne Säugetierfauna von Gödöllö b. Budapest. - Jb. ung. geol. Anst. 32, 1939. - - Beiträge zur Säugetierfauna der ungatischen alt- und jungpleistozänen Flußterrassen. - Ebendort 36, 1942. - - Eiszeit und eiszeitliche Faunaentwicklung. Z. f. Gletscherk. u. Glaziolgeol. 2, 2, 1953.

H. L. Movius: Villafranchian stratigraphy in Southern and Southwestern Europe. - The Journai of Geol. 5r, 1949. - - Zur Archäologie des unteren Paläolithikums in Südasien und im fernen Osten. - Mitt. anthrop. Ges. Wien 80, 1950. - - Old World Prehistory: Paleolithic. - Anthrop. Today, Univ. Chicago Press 1953.

K. P. OAKLEY: Man the tool maker. - London 1950.

A. PAPP \& E. Thenius: Über die Grundlagen der Gliederung des Jungtertiärs und Quartärs in Niederöstereich. - Sber. österr. Akad. Wiss. Wien, Math. Natw. Kl. I, 158, 1949.

M. Pfannenstiel: Die diluvialen Entwicklungsstadien und die Urgeschichte der Dardanellen. Geol. Rundschau 34, 1944.

J. Reid Moir: The culture of Pliocene Man. - Proc. prehist. Soc. East-Angl. 7, Part 1, 1932.

A. Rust: Altpleistozäne Artefakt-Funde im nordwestdeutschen Moränengebiet. - Mitt. geol. Staatsinst. Hamburg 23, 1954.

G. Schlesinger: Ein neuerlicher Fund von Elephas planifrons in Niederösterreich. - Jb. k. k. geol. Reichsanst. Wien 63, 1913. - - Die Mastodonten des k. k. Naturhist. Hofmuseums. - Denkschr. naturhist. Hofmus. I, 1917.

SkUtıl, Jos.: Palaeolithikum v Československu. - Obzor praehist. 11, 193S, 12, 1939.

W. Soergel: Die diluvialen Säugetiere Badens. - Mitt. großh. bad. geol. Landesanst. 60, 1914. - - Die geologische Entwicklung der Neckarschlinge von Mauer. - Paläont. Zeitschr. 15, 1933.

E. v. Szadeczky-Kardoss: Geologie der rumpfungarl. Kleinen Tiefebene. - Mitt. Berg-Hüttenm. Abt. Ódenburg 10, 1938.

J. Vieret: Le loess à bancs durcis de St. Vallier, Drôme, et sa faune mammifère villafranchienne. - Nouv. Arch. Mus. Hist. Nat. Lyon 4, 1954. 
P. Woldstedt: Das Vereisungsgebiet der Britischen Inseln und seine Beziehungen zum festländischen Pleistozän. - Geol. Jahrb. 65, Hannover 1950.

A. WinKLER-Hermaden: Ergebnisse und Probleme der quartären Entwicklungsgeschichte im östlichen Alpensaum außerhalb der Vereisungsgebiete. - Denkschr. österr. Akad. Wiss. Math. Natw. Kl. 110, 1955.

H. ZAPFE: Die Bedeutung der Wirbeltierpaläontologie für stratigraphische Fragen des Jungtertiärs im Wiener Becken. - Bergbau-Bohrt., Erdöl-Zeitung Wien 1949.

F. Zeuner: The Pleistocene Period. - Ray Society Vol. 130, London. - - Dating the Past. London 1946. - - The exhibition of Stone Age and Pleistocene Geology. - Univ. London 1948.

Manuskr. eingeg. 8. 3. 1956.

Anschriften der Verf.: Prof. Dr. H. Mohr, Wien I, Bräunerstraße 4-6. - Dr. Maria Mottl, Graz, Museum Joanneum. 